\title{
Daño social, neoliberalismo y la pandemia del Covid-19 en América latina
}

\author{
Social harm, neoliberalism and the Covid-19 \\ pandemic in Latin America
}

\author{
Ciro Martínez-Gómez \\ Carla Parraguez-Camus \\ Consultor independiente, Colombia \\ Consultora independiente, Chile
}

Resumen

El presente artículo trata de poner en evidencia cómo los daños que se han fraguado en las economías y las sociedades de América Latina a lo largo de más de cuatro décadas de vigencia del modelo neoliberal, potencian ampliamente los impactos negativos de la pandemia del Covid-19. Tomando como ejemplos a Santiago y Bogotá, se examina cómo los daños del neoliberalismo actúan, por un lado, de forma directa sobre los sistemas de salud, mediante el total desmonte de la capacidad para atender objetivos de salud pública y la segregación del acceso. Por otro lado, cómo los daños económicos y sociales del modelo se traducen en altos niveles de inequidad y pobreza, principalmente en dimensiones como la informalidad, los bajos niveles educativos, el hacinamiento y las limitaciones de acceso a servicios, que no sólo producen mayores niveles de contagio y de muertes, sino que también limitan la sostenibilidad y efectividad de las políticas.

Palabras clave: Neoliberalismo, daño, inequidad, pobreza, privatización, impacto de la pandemia.

\section{Abstract}

This article seeks to uncover how harms in Latin America generated under the neoliberal model over more than four decades ago enhance the negative impacts of the Covid-19 pandemic. Taking Santiago and Bogotá as examples, the article scrutinizes how neoliberal harms directly impact health systems given the state's incapacity in achieving public health goals and a rise in access segregation to health services due to Covid-19. Higher levels of contagion and deaths and the policies' poor effectiveness are linked to the previous social harms produced by neoliberalism in the region. The links between Covid-19 and inequality and poverty, especially regarding informality, low educational levels, overcrowding, and the limitations on access to services are uncovered.

Keywords: Neoliberalism, harm, inequality, poverty, privatization, Covid-19 pandemic impact. 


\section{INTRODUCCIÓN}

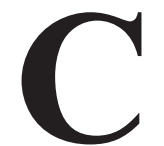

inco décadas después de la adopción del modelo neoliberal en Chile, ha quedado al descubierto que no sólo sus supuestos no funcionaban, sino que la adopción de sus principios generó enormes daños al florecimiento de las personas. En América Latina dichos daños se han traducido principalmente en la mantención de un nivel inaceptable de inequidad y la exacerbación de varias dimensiones de la pobreza entre ellas un grado muy alto de informalidad del empleo y de la economía en general. En los casos de Chile y Colombia, las reformas neoliberales implantadas en los sistemas de salud llevaron al total desmantelamiento de la capacidad de los Estados para atender objetivos de salud pública, al tiempo que se adoptaban esquemas de aseguramiento privado regidos estrictamente por el ánimo de lucro y con un corte marcadamente dualista, en los que se discrimina a la población pobre tanto en sus posibilidades de aseguramiento como en el acceso a la atención y en cuanto a la calidad de los servicios. En este contexto, a la llegada de la pandemia, América Latina en general y Chile y Colombia en particular presentaban indicadores que estaban entre los menores de los países de la Organización para la Cooperación y el Desarrollo Económico (OCDE) y del mundo en cuanto a camas hospitalarias, personal médico, salas de cuidado intensivo, laboratorios y otras dotaciones de salud. Las enormes inversiones requeridas para actualizar las capacidades para atender una crisis de salud pública de esta magnitud debieron ser asumidas a marchas forzadas por los países puesto que no hubo ninguna previsión para que el sector privado, que a lo largo de estas décadas se ha lucrado de los sistemas de salud, asumiera la atención en una situación de crisis como la presente. De esta manera, los gobiernos no contaron en ningún momento con la opción de adoptar políticas de reducción del impacto de la pandemia desde la salud pública, tales como las que se adoptaron en algunos países de Europa y Asia (pruebas masivas, rastreo de contagios, cerco epidemiológico), sino solamente con el recurso del confinamiento temporal de la población para generar un plazo durante el cual el sistema de salud pudiera actualizarse. Por otro lado, daños operados por el neoliberalismo como los grandes niveles de informalidad del empleo anulan la efectividad y la sostenibilidad de medidas de restricción. En suma, los daños del neoliberalismo a la sociedad, la economía y los sistemas de salud en los dos países en estudio, potencian ampliamente los impactos de la pandemia. 
El artículo consta de tres secciones y utiliza el enfoque de daño social para analizar las consecuencias del neoliberalismo en la región, al tiempo que visibiliza cómo estos daños se han amplificado en la pandemia. En la primera se explican y tipifican los daños que el neoliberalismo ha causado en la sociedad y la economía de América Latina. En la segunda se analiza el daño causado por la desestructuración de los sistemas de salud en Chile y Colombia y, en la tercera parte, se muestra evidencia empírica de las relaciones entre diferentes dimensiones del daño, especialmente la informalidad y la pobreza y los niveles de contagio y de muerte causados por la pandemia. El artículo concluye enunciando la importancia de la construcción de una agenda de reducción de daños a nivel latinoamericano y la imperiosa necesidad de retomar los objetivos de salud pública perdidos tras el neoliberalismo.

\section{Pandemia, daño social y neoliberalismo en América Latina}

El virus SARS-CoV-2 aparece en la ciudad de Wuhan en la República Popular China en diciembre del 2019. Este virus transita por países asiáticos y europeos durante el invierno del hemisferio norte y arriba a los países latinoamericanos hacia finales de la temporada de verano del cono sur. El 11 de marzo del 2020, la Organización Mundial de la Salud reconoce al Covid-19 como una pandemia global (OMS, 2020). El Covid-19 como enfermedad producida por el SARS-CoV-2, no solo ha dejado a la fecha (15-10-2020) cerca de nueve millones de contagiados en la región, sino también 300 mil muertes a consecuencia de la enfermedad (OPS, 2020).

Lo que ha ocurrido en los países desde entonces, induce a afirmar que se trata de una pandemia en salud, pero también una pandemia social. En términos de salud, "lo pandémico" de la enfermedad viene dado por su masividad, velocidad de propagación y la carencia de inmunidad frente al virus (OMS, 2020). Lo "social" de la pandemia se encuentra asociado a los estragos también masivos que la enfermedad ha causado al florecimiento humano. Aquí no solo nos referimos a la enfermedad y sus secuelas y a las muertes que ha ocasionado, sino también a las altas tasas de desempleo, el desmejoramiento de las economías regionales, las restricciones de la libertad y movilidad de las personas, las consecuencias psicosociales del confinamiento y el endeudamiento de las familias para lograr el acceso a los servicios de salud. El Covid-19 como enfermedad ha venido a confrontar la configuración y capacidades de los sistemas de salud y seguridad social de la región, al tiempo que nos plantea una oportunidad para reflexionar sobre la constitución actual del tejido social latinoamericano y los daños 
sociales que se han fraguado y consolidado como consecuencia y a lo largo del proceso de implantación del modelo neoliberal en la región.

En este artículo utilizamos el enfoque de daño social como medio para "unir los puntos" entre los daños, la reconfiguración de la estructura social causada por el neoliberalismo y la pandemia actual. Este enfoque nos ofrece una visión alternativa que nos permite entender, por ejemplo, que las 300 mil muertes de personas por Covid-19 en América Latina a septiembre de 2020 (OMS, 2020) no son eventos naturales, como tampoco parte de la "lotería de la vida". Este tipo de daños no resultan completamente atribuibles al comportamiento irresponsable y personal de los individuos que no ejercen prácticas de auto-cuidado y de respeto de las cuarentenas, sino también - y en gran medida - la pandemia y sus estragos en el florecimiento humano, relatan daños más estructurales que venían fraguándose en la región latinoamericana.

El enfoque de daño social nos ayudará a visibilizar cómo los procesos y dinámicas que se forjan en el corazón del tejido social pueden ser capaces de poner trabas al florecimiento de los individuos en las sociedades (Parraguez, 2017: 38). Si bien los daños usualmente se manifiestan frente a nuestra vista como lesiones ya en curso (desigualdad, segregación, desconfianza, entre otros) éstos serían resultado de procesos, relaciones y dinámicas que los individuos a través de prácticas y esquemas de institucionalización van fraguando repetida y sistemáticamente a lo largo del tiempo en dichas sociedades. Aun cuando existen eventos que para muchas personas pueden ser considerados como "irritantes", "desagradables", "molestos" o "poco éticos", estos en última instancia no son necesariamente dañinos. Lo que separa el daño de lo que no lo es, es su sistematicidad en la forma de constreñir al florecimiento humano (Hillyard y Tombs, 2004). La idea de sistematicidad del daño social será clave para entender las lesiones acontecidas en sociedades latinoamericanas bajo el neoliberalismo.

El neoliberalismo como toda forma de organización capitalista, posee estrategias de reducción de daños sociales al tiempo que genera otras formas de constreñimiento al florecimiento humano (Pemberton, 2016). Lo interesante de este tipo de sociedades es que - como indica Springer (2015: 7) - "el neoliberalismo no existe como un estado final finito". Siempre pareciera tener una capacidad adaptativa la cual le permitiría seguir operando sin importar los episodios de crisis socio-económicas profundas (Peck, 2010). En el caso latinoamericano, la historia del neoliberalismo comienza en 1973 en Chile en el contexto de una dictadura militar liderada por Augusto Pinochet (Taylor, 2006; Harvey, 2007). Sin embargo, el neo- 
liberalismo se consolida en la región durante las décadas de los ochenta y noventa a través de las políticas del Consenso de Washington (Puello, 2015). En ambas situaciones, los esquemas neoliberales han ido transitando desde un neoliberalismo de manual económico a un neoliberalismo con rostro humano (Atria, 2013), probando sus características de adaptación y transformación, aun cuando algunos daños y lesiones siguen persistiendo.

Las dinámicas de generación de daño social en la región se entrelazan con las características generales a través de las cuales el neoliberalismo reconfigura las relaciones sociales y las relaciones entre el estado y la ciudadanía. Como sabemos, el neoliberalismo tiene que ver con una forma de entender el desarrollo (Hill, Wald y Guiney, 2016), la ciudadanía, las aspiraciones sociales, valóricas y de discursos (Lewis, 2016). En términos de práctica política, el neoliberalismo reconfigura las relaciones entre propiedad estatal y privada girando el foco de las políticas públicas a lo que la literatura ha descrito como la marketización, desregulación, liberalización y privatizaciones (England y Ward, 2016). La arquitectura estatal de este paradigma reconstituye las relaciones sociales de una forma en que los vínculos entre Estado-Mercado-Familia tienden a proveer mayor responsabilidad a los individuos respecto a su seguridad social.

En 1989 la región decide adoptar al neoliberalismo a través un set de políticas prescriptivas diseñadas en Washington, a cambio de recibir ayuda financiera del Banco Mundial y el Fondo Monetario Internacional. La acumulación de la deuda externa y el consecuente colapso económico de 1982 había dejado a los países con escaso margen de acción para negociar. De acuerdo con Williamson (2008), el proyecto del Consenso de Washington fue promocionado solo como un set de reformas económicas que ayudarían a balancear la economía a través de la disciplina fiscal, el redireccionamiento del gasto público, la liberalización económica, la inversión extranjera y las privatizaciones. Sin embargo, como sabemos, en realidad "estas políticas fueron mucho más que una agenda económica" (Stiglitz, 2008: 45) porque ellas también terminaron trayendo aparejadas nuevas formas de subjetividad y una forma particular de manejo estatal que reconfiguró las relaciones sociales.

La extensión de las implicaciones de las políticas del Consenso de Washington en la región podría a grandes rasgos sintetizarse en tres olas de privatizaciones. La primera ola de privatización se orientó a las empresas nacionales y productos de consumo; la segunda ola se focalizó en infraestructura y telecomunicaciones, y la tercera ola significó la privatización de sectores sociales tales como el área de pensiones, salud y educación. Los 
resultados sociales asociados con estas privatizaciones no fueron buenos. Como Lloyed-Sherlock (2009) documenta, en vez de reducir las disparidades socio-económicas en la región, muchas intervenciones en los sistemas de bienestar tales como las reformas en educación, salud, y protección social terminaron activamente contribuyendo a aumentar las brechas. Sobre esto, la Comisión Económica para América Latina y el Caribe (CEPAL) ha reportado en su Panorama Social a través de los años, que la estructura productiva sigue presentando un desarrollo desigual de las fuerzas productivas y las relaciones sociales de producción, que a su vez llevan a diferencias en los niveles de productividad, distribución de ingresos y acceso al consumo. Todas disparidades que han tendido sistemática y persistentemente a afectar negativamente a los grupos más vulnerables, tales como mujeres, jóvenes y personas con bajos niveles educativos (CEPAL, 2010), las áreas rurales y zonas más apartadas de los países.

Como forma de superar estos resultados negativos, se estableció un segundo set de políticas orientadas a generar reformas legales, instituciones reguladoras, flexibilidad en el mercado laboral y una batalla focalizada hacia la pobreza (Green, 2003). Sin embargo, las correcciones del modelo llegaron a destiempo. Varias voces han comenzado a cuestionar los así llamados modelos sociales de economía de mercado latinoamericanos (Mayol, 2012). Hasta ahora, las criticas principales se han centrado en dos temas relacionados: desigualdad de ingresos y oportunidades, y la privatización de los derechos sociales (Atria et al., 2013; Solimano, 2015). Ambas preocupaciones apelan a los costos individuales y sociales a través de los cuales los modelos neoliberales latinoamericanos han construido sus logros. Lo anterior ha servido para la generación de un "caldo de cultivo" para la segregación, discriminación y comportamientos individualista en las sociedades (Ruiz, 2013; Moulian, 1998) previo a la crisis generada por la pandemia del Covid-19.

\section{Tipos de daño social en el espacio pre y pandémico}

Desde el enfoque de daño social, las lesiones ocasionadas por el neoliberalismo en la región podrían agruparse en tres tipos de daños sociales: relacionales, autonómicos, y físicos/ psicológicos. Los daños relacionales dicen relación con situaciones en donde las personas se encuentran parcial o totalmente excluidos de la estructura social. Por ejemplo, daños relacionales pueden ser vinculados a desigualdades estructurales respecto de ingresos y oportunidades disponibles. Sin embargo, también este tipo de daños pueden ser considerados cuando existen bajos niveles de confianza 
interpersonal o desconfianza en las instituciones de la sociedad, dado que la desconfianza favorece relaciones antagónicas entre instituciones y grupos. Así también, uno podría esperar la conformación y manifestación de daños sociales cuando los individuos poseen bajos niveles de integración en las sociedades, lo que tiende a actuar como catalizador de diferentes formas de discriminación y segregación. Por su parte, los daños autonómicos dan cuenta de situaciones en las cuales los individuos tienden a perder el control sobre sus medios de vida en razón de satisfacer sus necesidades. La autorrealización de los individuos se encuentra en riesgo cuando estos no tienen la posibilidad de realizar decisiones autónomas y cuando de alguna forma se encuentran "atrapados" por sus circunstancias de vida. Así, los daños de autonomía pueden tomar diferentes formas como, por ejemplo: exclusión laboral, estratificación de logros educativos y accesos diferenciados a la esfera del consumo/servicios.

Respecto a los daños físicos y psicológicos, estos se forjan en el tejido social cuando los individuos no pueden asegurar la producción y reproducción de sus medios de subsistencia. Es decir, cuando los individuos no pueden acceder a alimentos, techo, abrigo y/o a sistemas de salud en caso de enfermedad. La misma racionalidad aplica para los daños sociales de tipo psicológico. La reproducción de la vida humana implica también que los individuos sean capaces de sostener sus capacidades mentales a niveles saludables. Y al hacerlo, altos niveles de estrés, hacinamiento o depresión pueden llevar a la reducción de las posibilidades de reproducción material de subsistencia, en la medida en que los cuerpos de los individuos no pueden ser usados como vehículos para obtener sus medios de vida.

Utilizando este marco conceptual, uno podría identificar a lo menos tres núcleos que han contribuido a intensificar la formación y agudización de daños físicos, psicológicos, autonómicos y relacionales de la región en el espacio pre-pandémico a consecuencia de las reformas neoliberales. Primero, aun cuando existe una expansión del gasto social focalizado en la región como parte del conglomerado de acciones correctivas a la primera y segunda ola de recomendaciones del Consenso de Washington, las tendencias de privatización/desregulación en sistemas de bienestar y seguridad social han persistido en el traslado de la responsabilidad colectiva al riesgo individual lo que deja una gran masa de individuos expuestos a distintos tipos de lesiones sociales. Se intensifican daños físicos en la medida que no todos los individuos logran tener acceso a sistemas de salud, educación y pensiones. La privatización de los sistemas de manejo de riesgos sociales necesariamente se encuentra asociado a una transacción monetaria en 
esquemas de privatización, la que a su vez se encuentra estratificada por el mercado del trabajo y el acceso a mecanismos de crédito.

El Covid-19 volvió a reforzar lo que la literatura en salud viene alertando hace tiempo. Los accesos y oportunidades de tratamiento frente a enfermedades allí donde se encuentran privatizados están determinados por la capacidad de pago de los individuos y sus familias. La CEPAL y OPS (2020: 14) al respecto indican que "en promedio, los hogares de la región deben cubrir más de un tercio del financiamiento de la atención de salud con pagos directos de bolsillo (34 por ciento)." Así, diferencias estratificadas por ingresos se agudizan en pandemia cuando se analiza la distribución territorial de las posibilidades de testeo, tratamiento y trazabilidad efectiva de la población.

Segundo, la concentración de ingresos y sus impactos negativos en la equidad puede considerase como un segundo núcleo que facilita la formación de daños sociales especialmente del tipo relacional. América Latina sigue siendo la región más desigual del mundo y este patrón no se ha revertido. De acuerdo a la CEPAL (2019a: 21), "aunque entre 2002 y 2014 la desigualdad de ingresos disminuyó de manera significativa, a partir de 2015 esa tendencia se ralentizó...el promedio regional medido por el índice de Gini bordeó los 0,465 en 2018”. La concentración de ingresos es contraproducente para el desarrollo sostenido de los países. La desigualdad y la falta de equidad tienden a generar menor número de acciones solidarias y la pérdida de construcción de proyectos comunes. Lo anterior, explicaría por ejemplo que las tasas de crímenes y victimización continúen en alza, siendo una de las regiones con las tasas de homicidios más altas en el mundo (Muggah y Aguirre, 2018).

La concentración de ingresos no mejorará con la pandemia. Organismos internacionales anticipan la agudización de impactos negativos en la equidad dada la contracción económica, la persistencia de las altas tasas de empleo informal en la región, así como la fragilidad de los sistemas de salud y protección social. En este sentido, se anticipa que persistan situaciones de exclusión y marginalidad las cuales redundarían en una mayor vulnerabilidad de las personas ante el avance del Covid-19. La pérdida de empleo, ingresos y restricciones de movilidad dadas las cuarentenas, dejarían aún más desprotegido a 54 por ciento de personas de la región que, según las estimaciones, realizan trabajos informales, y se proyecta un alza en la tasa de incidencia de la pobreza en siete puntos, elevando la proporción de pobres en la región a 37.3 por ciento. 
Tercero, la dependencia del crédito en los hogares en la región sigue aumentando (Ruiz-Tagle, 2017). A una estructura salarial de bajos ingresos, el mecanismo del endeudamiento de las personas ha resultado ser una de las estrategias más utilizadas por los hogares. Los hogares más endeudados de la región son los chilenos con un porcentaje de endeudamiento de 45.4 por ciento para 2018 seguido por Brasil y Colombia con 28.2 y 27 por ciento respectivamente (CEPAL, 2019b: 43). Para el caso chileno, el Banco Central ha actualizado esta cifra a 2019 indicando que la deuda de hogares alcanzó 75 por ciento del ingreso de las familias. El concepto de endeudamiento y sobreendeudamiento son problemáticos desde el punto de vista de análisis de daños sociales. La lógica de la deuda inculca la idea de que todos en la sociedad pueden ser dueños de "algo" (carros, casas, etc.), y sin embargo, este sentido de propiedad tiende a predisponer a las personas a comprometerse con discursos centrados en la meritocracia, sacrificio y resilencia. Incluso cuando los salarios no son suficientes para satisfacer las necesidades esenciales y no esenciales, el modelo de endeudamiento ayuda a consolidar las explicaciones conductuales de las lesiones sociales, porque la deuda siempre es individual. Es decir, se presenta como el resultado de una "opción personal" o como una oportunidad individual para aprovechar los beneficios del esquema neoliberal. El círculo de la deuda reduce daños de tipo físico en la medida que da acceso a los individuos a una participación en el mercado. Sin embargo, la deuda también induce a comprar bienes no esenciales generando sociedades y mentalidades de consumo (Moulian, 1998). El sobreendeudamiento sigue un patrón similar, causa daños sociales de autonomía ya que las opciones se encuentran mediatizadas por esquemas de pago, como también pueden generar daños físicos en razón del no pago de las deudas. El endeudamiento no es una conversación separada a la tendencia de privatización de los sistemas de seguridad social y riesgos. Dados los esquemas privatizados de los sectores sociales en la región, los deciles más pobres han encontrado en el acceso al crédito una fórmula para navegar las contingencias.

Dado que en muchos países del espacio latinoamericano el acceso a diagnóstico y tratamiento del Covid-19 implica copagos por parte de los individuos, se anticipa un "efecto catastrófico y empobrecedor en el futuro inmediato" (CEPAL-OPS, 2020: 14). Si a lo anterior le sumamos el alza de mecanismos de crédito y endeudamiento como estrategias para paliar la cesantía o la reducción de ingresos, el panorama se vuelve aún más preocupante en el corto plazo. Hogares con ingresos reducidos o con trabajadores cesantes con altas tasas de endeudamiento se sumarían como factores im- 
portantes a la "tormenta perfecta" que enfrentaremos no solo en sino post pandemia.

El Covid-19 hace que los daños sociales físicos, psicológicos, autonómicos y relacionales que el neoliberalismo ha dejado a su paso, se presenten de forma más nítida frente a nuestros ojos, así como también las relaciones entre tales daños. Primero, el Covid-19 es democrático en su forma de contagio (todos podemos contagiarnos), sin embargo, como las dinámicas del tejido social presentan desigualdades estructurales en la región, estas permean las formas en que las personas perciben o experimentan la enfermedad, las cuarentenas y la disposición y oportunidad de tratamiento en los sistemas de salud. Estas sociedades fragmentadas y basadas en la desconfianza interpersonal e institucional no ayudan en la medida que, por una parte, se elevan los descreimientos de la ciudadanía respecto al número de contagiados, testeos realizados y posibilidades de trazabilidad de casos, y por otro, se desconfía del "otro" respecto a las medidas de autocuidado que toma y las posibilidades de ser contagiado por él. Dos factores interrelacionados que plantean desafíos importantes no solo respecto a las capacidades de respuesta de los sistemas de salud frente a la crisis, sino también complejiza o directamente neutraliza los sistemas de cuarentenas.

Segundo, las medidas tomadas en torno a la prevención del Covid-19 y no la enfermedad en sí misma agudiza daños a la autonomía. Como señalamos anteriormente, los daños de autonomía dicen relación con la carencia de control de los individuos sobre decisiones que atañen a su propia vida. En esta área destacan las condiciones de hacimiento de la población, la imposibilidad de muchos de realizar teletrabajo (en especial trabajadores manuales) y la brecha de acceso a internet y computadores que existe en los hogares pobres latinoamericanos a fin de recibir clases online ya que las escuelas se encuentran cerradas.

Tercero, los daños sociales de carácter físicos y psicológicos en pandemia son variados. Estos abarcarían desde la aparición de gatillantes de enfermedades de salud mental a consecuencia o derivadas del confinamiento tales como estrés, depresión, ansiedad hasta el resultado de muerte allí donde las personas no pudieron recuperarse del Covid-19.

Así expuesto, las intersecciones entre daños sociales, neoliberalismo y la pandemia sitúan a la región en una situación delicada. Sabemos que la enfermedad del Covid-19 se contrae de forma personal y posee reglas de contagio bastante bien establecidas. ${ }^{1}$ Aunque una incertidumbre no menor

1 De acuerdo al Centro de control y prevención de Enfermedades, el contagio se produce a través del contacto cercano entre personas y por "gotitas respiratorias que se producen cuando una persona tose, estornuda o habla” (CDC, 2020), así también personas sin síntomas pueden propagar 
la produce el hecho de que personas asintomáticas pueden esparcir el virus. En todo caso, las formas de evitar contagiarse y contagiar a otros dependen de conductas personales. Sin embargo, dadas las mismas reglas que impone la forma de contagio, la única forma de superar al virus es de manera colectiva. Las políticas del Consenso de Washington sobre las formas de entender el desarrollo, la ciudadanía, los hábitos de consumo, las premisas sobre la libertad y la individualidad utilizando principios de mercado, se han instalado a contra sentido de lo que nos impone la pandemia para salir de ella. Lo individual sobre lo colectivo como la fórmula de prosperidad individual y social que dejaron las enseñanzas del neoliberalismo, son esquemas de "governmentaly" diría Michel Foucault (2002) ya en curso en nuestros cuerpos, prácticas, políticas e instituciones. Todas estas son razones que, como podría haberse previsto, están haciendo difícil articular una respuesta colectiva como la requerida para superar la pandemia en el corto y largo plazo.

\section{El daño neOliberal a los Sistemas de SALUd de Chile y Colombia}

Corresponde ahora indagar qué características ha presentado el proceso de estructuración del daño del neoliberalismo en el sector salud en América Latina. Utilizamos para ello, como ilustración, los casos de Chile y Colombia, países en los que tal proceso se ha venido consolidando desde la década del ochenta y la década del noventa respectivamente, y ha incluido entre otros aspectos, una reformulación total del concepto de salud, no ya como un servicio público sino como un bien transable en el mercado; una reconfiguración de los roles del Estado y del sector privado en la provisión de los servicios de salud; y un fuerte cambio de la institucionalidad y la normativa que interviene en las diferentes etapas y aspectos de los sistemas de salud. Esta realidad de sistemas de salud neoliberales con larga trayectoria, consolidados, es en la que se encuentran los dos países al momento del arribo de la pandemia. Y es una situación que en gran medida limita las orientaciones y la efectividad de las políticas y las acciones que pueden emprender los gobiernos para encararla.

Un aspecto muy importante de la producción de daños por parte del neoliberalismo es su capacidad de irse transformando y readecuando a partir del modelo ideal. La implantación del modelo a los sistemas de salud en Chile y Colombia ilustra claramente tal capacidad adaptativa, que se

el Covid-19. Hay aún discusión sobre la permanencia de las partículas con virus en el aire y su duración en distintas superficies. 
expresa en la introducción sucesiva de "parches" mediante los cuales se trata de suavizar la percepción pública de los impactos del modelo, para facilitar la consolidación de su hegemonía. En Chile, esa capacidad adaptativa se demostró en los cambios que se hicieron al modelo al pasar de la dictadura militar a los gobiernos democráticos. En Colombia, se adoptó un modelo al que, con base en la experiencia chilena, ya se le habían introducido ciertas adaptaciones, que le aportaban, al menos en el discurso, un "rostro humano". Estas adaptaciones pueden observarse también en el sector salud. Por ejemplo, la reducción drástica del gasto público en salud y el cierre de la mayoría de las instituciones prestadoras de servicios pertenecientes al sector público, se justificó con el discurso, profusamente divulgado, acerca de la mejora de la eficiencia del gasto mediante la focalización (y su instrumental técnico). Detrás de esto, en la práctica, no sólo no se habían atenuado los daños del modelo sino que se habían extremado algunas de sus recetas.

El proceso de establecimiento del neoliberalismo en los sistemas de salud en Chile y Colombia, así como la configuración de los daños en ese aspecto de la protección social, presenta varios puntos comunes. En primer lugar, se puede resaltar cómo, tanto la Constitución Política Nacional (CPN) adoptada en Chile en 1980, como la de Colombia, adoptada en 1991, legitimaron y otorgaron un piso constitucional a la aplicación de los principios neoliberales en los sistemas de salud. En efecto, las dos constituciones abren el espacio para la participación privada en la provisión de los servicios de salud, función que hasta entonces había sido esencialmente pública. También se consagra constitucionalmente el principio de la libre elección de los usuarios entre el sector privado y público, la posibilidad de establecer cotizaciones obligatorias (aseguramiento) y la reducción de la intervención del Estado que se limita a las actividades de coordinación, evaluación y control del sistema. En la CPN de Colombia se perciben algunas adecuaciones al modelo neoliberal que, como se ha dicho, eran probablemente derivadas de la experiencia de diez años de operación del sistema neoliberal en Chile, entre ellas, consagrar la organización descentralizada del sistema, abrir el espacio para la participación de la comunidad en la organización de los servicios (aunque nula en la práctica) y la definición de la parte de las funciones relacionadas con la salud, que quedan a cargo del Estado, tales como la promoción y el saneamiento ambiental (las actividades no rentables). Es importante señalar que las dos CPN encierran contradicciones entre los principios que acogen. Por un lado, se establece como deber del Estado la protección (Chile) o garantía (Colombia) del acceso a 
los servicios de promoción, protección y recuperación de la salud, e incluso en este último país se habla del principio de universalidad, gratuidad y obligatoriedad de la atención básica, al tiempo, que, como podía preverse, y efectivamente ocurrió, tal protección y garantía no podrían cumplirse en el segmento de servicios que sería manejado por el sector privado.

Aparte del piso constitucional, la implementación de las reformas neoliberales de los sistemas de salud de los dos países se basó en procesos previos que afectaron la institucionalidad y los recursos de los sistemas de salud preexistentes, llevándolos a una situación crítica. Esta situación confería legitimidad y aceptación pública a las reformas que iban a ser promulgadas. En ambos países, de manera congruente con el principio neoliberal de reducción del tamaño del Estado, el gasto en salud se había reducido sistemáticamente en la década anterior a las reformas. En Chile, el gasto per cápita en salud cayó 64 por ciento entre 1974 y 1979, lo que se tradujo principalmente en recortes a la inversión en infraestructura y en los ingresos de los trabajadores de la salud, y llevó al sistema a un punto de crisis a finales de los ochenta (Taylor, 2006: 93). En Colombia, el gasto en salud como porcentaje del PIB había decrecido sistemáticamente durante la década de 1980, en 1990 alcanzaba sólo 1.8 por ciento del PIB, bastante por debajo del promedio latinoamericano de 2.4 por ciento; afectando principalmente a la inversión en infraestructura que cayó sistemáticamente desde 1980 hasta 1990 (Molina et al., 1994: 6-8). Las reformas de la salud tuvieron como trasfondo cambios legales y reestructuraciones institucionales orientadas principalmente a la descentralización de funciones y de manejo de recursos ${ }^{2}$ y tuvieron como efecto el recorte de funciones de los Ministerios de Salud y otras instituciones del sistema. La percepción de una situación de crisis y de pésima calidad de los servicios en los sistemas imperantes, creaban un ambiente propicio para introducir las reformas del sistema, presentándose la privatización y demás cambios como la alternativa necesaria y oportuna.

\section{Estructura y operación de los sistemas neoliberales de salud}

Los sistemas neoliberales de salud finalmente implantados en Chile y Colombia presentan muchas semejanzas en sus principios, estructura, funcionamiento y operación. En este apartado se examinan las similitudes de

\footnotetext{
2 En Chile, el Decreto Ley (DL) 2763 de 1979 crea el FONASA, que sería el encargado de la recaudación y administración de los recursos de la salud estatal, establece la función descentralizada del sistema público de salud y traslada (gradualmente) la función de atención primaria a los municipios. En Colombia, la Ley 10 de 1990 estipulaba el paso gradual de las finanzas de la salud a los departamentos y municipios.
} 
los dos sistemas como método para indagar cuáles son los daños que estos sistemas producen y los mecanismos a través de los cuales actúan.

En primer lugar, los principios generales en que se fundamentan las reformas de los sistemas de salud de Chile y Colombia ${ }^{3}$ son los mismos, ya que son inherentes a su enfoque neoliberal. Entre ellos están la necesidad de permitir la participación del sector privado en la gestión y prestación de los servicios de salud, junto con el convencimiento de que tal intervención mejoraría la eficiencia y eficacia y aseguraría "un mayor acceso y una debida protección al derecho a la salud" (Zamora, 2012: 1). Otro principio del que se parte es la ineficiencia y duplicidad que implica el gasto del Estado en salud y su método de canalización a través de subsidios a la oferta (Santamaría et al., s/f: 9).

En esencia, los sistemas creados en los dos países son duales o mixtos. En Chile la dualidad se refiere a la existencia de un Sistema Privado (ISAPRE) y un Sistema Público de Salud (FONASA). En Colombia, la dualidad se presenta entre el Régimen Contributivo (RC) que cubre a la población con capacidad de pago y el Régimen Subsidiado (RS) que cubre a la población pobre. Aunque en Colombia se ha querido establecer un sistema único, en la práctica se presenta una dualidad entre el sector privado, cuya gestión y administración está a cargo de las Entidades Promotoras de Salud (EPS) mientras que la responsabilidad sobre la financiación y operación del RS recae en el Estado, principalmente en los entes territoriales. En ambos países, los servicios privados se organizan bajo un enfoque de aseguramiento, manejado por empresas privadas que actúan como corredoras de seguros de salud, que (en principio) no cuentan con servicios propios, sino que contratan personal e infraestructura según sea requerido (Taylor, 2006: 94).

En cuanto a los recursos para su funcionamiento, en los dos países, el sistema privado es financiado exclusivamente por las cotizaciones obligatorias de los trabajadores, ${ }^{4}$ mientras el sistema público (o el RS) se finan-

3 En Chile, el DFL No. 3 de 1981 creó el Sistema Privado de Salud y dio origen a las Instituciones de Salud Previsional (ISAPRE). En Colombia, la Ley 100 de 1993 crea el Sistema General de Seguridad Social en Salud (SGSS), define a las EPS (Entidades Prestadoras de Salud) como principal intermediario.

${ }^{4}$ En Colombia, la cotización es un porcentaje fijo (12.5 por ciento) del nivel de ingresos. En el caso de los trabajadores dependientes, las contribuciones las cubren el trabajador (cuatro por ciento) y una parte el empleador (8.5 por ciento). En el caso de los independientes, ellos cubren la totalidad de la contribución. Suelen tener ingresos más elevados que la mayoría de los trabajadores asalariados, cotizan sobre un salario base inferior al real, resultando sus servicios subsidiados por los aportes de los trabajadores asalariados. Este es uno de los efectos perversos del sistema. En Chile, la cotización es siete por ciento del salario de los trabajadores. No hay aporte de los empleadores. Los aportes son de propiedad de los afiliados. Se espera que esto lleve a una mayor exigencia de calidad en los servicios. 
cia con los aportes obligatorios de sus afiliados y con subsidios del tesoro público $^{5}$ (Ministerio Protección Social, s/f: 515). Otra fuente de recursos son las cuotas moderadoras y los copagos creados con el objetivo de evitar el "riesgo moral". ${ }^{6}$ En cuanto a los servicios, todos los afiliados reciben, como mínimo, un paquete de beneficios establecido por las normas. En Colombia este paquete, denominado el Plan Obligatorio de Salud (POS $)^{7}$ fue adoptado desde el principio de la instauración del sistema. ${ }^{8}$ En Chile se denomina el Plan de Acceso Universal con Garantías Explícitas (AUGE) e hizo parte de las reformas introducidas por los gobiernos democráticos. ${ }^{9}$

El montaje de los sistemas de salud basados en los principios del mercado de aseguramiento privado produce daños a la salud y a la sociedad latinoamericana. Existen unos daños de carácter general asociados a la esencia capitalista de los nuevos sistemas de salud, entre ellos el abandono de los objetivos de salud pública, con sus implicaciones negativas sobre el tejido social, la equidad, la solidaridad y el florecimiento de los individuos. Estos son daños cuyo impacto es difícil de evaluar y requieren análisis a fondo del funcionamiento de los sistemas. Aun así, en las evaluaciones de la operación interna de los sistemas frente a los requerimientos de la libre competencia se hacen evidentes las limitaciones que surgen de las previsibles "imperfecciones del mercado" de salud y los daños que de ellas se derivan. Entre los daños más importantes detectados están el sesgo estructural en contra del sistema estatal, la desigualdad territorial del acceso y la discriminación de la población pobre.

La dependencia de los recursos públicos introduce sesgos estructurales en contra del sistema estatal (o sistema subsidiado). Este debe cubrir una parte mayoritaria de la población, precisamente de los segmentos más pobres. En Chile, en 2015, el sistema público debía cubrir a más de 75 por ciento de la población con un tercio de los recursos de cotizaciones y el

\footnotetext{
5 Además, se cobra un copago o cuota moderadora por la atención, relativa al nivel de ingresos y al tipo específico de atención, cuyos recursos son marginales.

${ }^{6}$ Se denomina así el riesgo de una sobreutilización de los servicios por parte de los usuarios.

7 En principio hubo un paquete de servicios para el RC (POS) y uno que incluía menos servicios para el RS, denominado POS-S.

8 En el sistema colombiano, estructurado 10 años después del de Chile, se introdujeron mejoras al funcionamiento del sistema privado de aseguramiento entre ellos, una única bolsa de procedimientos y medicamentos, y un sistema único donde todas las entidades prestadoras de salud (IPS) públicas y privadas compiten por los contratos de las EPS. También se estableció un sistema de compensación entre personas de diferentes perfiles de riesgo.

9 En Colombia, opcionalmente se pueden adquirir planes de atención complementaria (PAC) y planes de medicina prepagada que ofrecen mayor contenido que el POS y mayor calidad. Para obtenerlos es prerrequisito pertenecer al Régimen Contributivo y pertenecer a una EPS. Una parte importante de la población acude a estos planes como medio de asegurarse una atención mínimamente adecuada y prescinde completamente de utilizar el POS, presentándose un desperdicio de recursos y aumento del gasto de bolsillo. Aun así, la ineficiencia del sistema ha llevado a una degradación de la calidad aún de estos costosos planes de aseguramiento.
} 
gasto por beneficiario en el sector privado era cuatro veces el del sector público. En consecuencia, la calidad de atención del sector privado es muy superior puesto que pueden pagar mayores salarios y vincular personal más calificado (Taylor, 2006). En Colombia, los mecanismos de financiación y compensación entre las fuentes de los recursos son extremadamente complejos ${ }^{10}$ hay demoras en el traslado de los recursos y su desviación a otros fines, situación que afecta principalmente al RS y a los entes territoriales que ven mermada su capacidad de prestar los servicios.

La discriminación en el acceso a los servicios y en la calidad de la atención se produce por varias vías. En Chile, el sistema privado cobra primas más altas, tiene plena libertad al alza y sus tarifas se basan en el análisis del riesgo individual, principalmente en consideraciones de edad, género y estado de salud. Como resultado, la población de mayor edad y las mujeres en edad reproductiva, deben pagar altas primas o son simplemente rechazadas. Puede decirse que el sistema es dedicado sólo a adultos jóvenes, de mayores ingresos y con menor probabilidad de requerir atención. En Colombia, aunque el financiamiento del sistema se basa en un monto único (UPC) por beneficiario y un paquete único de servicios, en la práctica la disponibilidad de servicios para el régimen subsidiado es muy limitada, normalmente sólo se cuenta con centros de salud de baja complejidad en la mayoría de los municipios lo que implica grandes desplazamientos y costos para acceder a los servicios en las principales ciudades. En una investigación al respecto, 49 por ciento de las IPS públicas de primer nivel no contaban con los requisitos definidos por el sistema para prestar el nivel más bajo del POS subsidiado (Ministerio de Protección Social, s/f: 536).

Aunque los sistemas neoliberales de salud se construyeron sobre la base de un principio de libre elección, en la práctica la movilidad está altamente restringida, por la asimetría de la información sobre la oferta y por barreras a la afiliación y desafiliación. En Chile, las evaluaciones concluyen que, para la mayoría de la población, no se ha incrementado la libertad de escogencia debido a la discriminación por riesgo y los altos costos de las ISAPRE. En Colombia, el sistema de pago a las EPS por Unidades de Capitación según el número de afiliados, conduce a que se retengan los afiliados demorando la expedición de los requisitos para el cambio de EPS.

${ }^{10}$ En el financiamiento del RC sólo intervienen los afiliados como fuente de recursos con sus aportes, las EPS como recaudadoras y el FOSYGA. En el RS, intervienen, como fuentes, los Recursos de los Ingresos Corrientes de la Nación (ICN), recursos transferidos a los entes territoriales o Situado Fiscal (que difieren según categorización de estos entes), recursos propios de los entes territoriales, rentas cedidas; las administradoras del régimen subsidiado (ARS), el FOSYGA y los Fondos Territoriales de Salud, que son los que al final, giran los recursos a las ARS. 
Las superintendencias de salud fueron creadas en los dos paíse ${ }^{11}$ para ejercer el seguimiento evaluación y control de los sistemas de salud. En la práctica estos organismos operan como órganos correctores de las "fallas del mercado" y no realizan evaluación de la calidad de los servicios. Aparte de ello, en Colombia, la Superintendencia Nacional de Salud nunca ha contado con los recursos suficientes ni con el poder sancionatorio requerido para realizar una verdadera vigilancia y control (Ministerio Protección Social, s/f: 516). Al nivel de los entes territoriales, las funciones de inspección, vigilancia y control se ejercen de manera descentralizada, es decir que la vigilancia recae sobre las autoridades territoriales, que son al mismo tiempo las encargadas de asegurar el flujo de los recursos del sistema y que evidentemente no tienen ninguna motivación para denunciar fallas de las que son responsables (Ministerio Protección Social, s/f: 526). Esto se ha prestado para fomentar el favoritismo en los contratos, la desviación de recursos y en general un manejo corrupto del sistema, que ha lesionado gravemente la calidad de la prestación de los servicios.

\section{El daño neOliberal a loS Sistemas de SALUd Y LOS IMPACTOS DE}

\section{LA PANDEMIA}

Los daños económicos y sociales infligidos por el neoliberalismo se refieren fundamentalmente al mantenimiento de una elevada concentración del ingreso, un nivel también elevado de pobreza y vulnerabilidad de los hogares y sobre todo un crecimiento sin precedentes de las actividades informales en la economía. A estos, en los dos países que estamos analizando, se suman los daños causados por las reformas neoliberales a los sistemas de salud. En lo que sigue se trata de establecer cómo esta suma de daños potencia los efectos de la pandemia y limita las posibilidades de los gobiernos para enfrentarla de manera efectiva y sostenible.

Un repaso de los principales indicadores de infraestructura de salud en Chile y Colombia, permite constatar la precaria situación con la que se encaraba la pandemia. Según los datos de la OCDE para $2018^{12}$ (OCDE, 2020), Colombia y Chile contaban con sólo 1.7 y 2.1 camas hospitalarias por mil habitantes, respectivamente, lo que los colocaba en los puestos 38 y 39 entre 42 países de la OCDE analizados; comparados con Japón, Corea y Alemania que contaban con 13,12.4 y ocho camas hospitalarias por mil habitantes, respectivamente. En 2018, el promedio mundial de camas

11 En Colombia, fue creada dentro de la Ley 100, como parte del sistema. En Chile, la función la ejercía el Ministerio de Salud, pero en 2005 se introdujo esta adaptación o parche al sistema. 12 El informe de 2020 consultado incluye los datos de la fecha más reciente obtenida de los países. Algunos de los indicadores corresponden a 2019. 
hospitalarias era de 3.1 por mil habitantes y Colombia ocupaba el puesto 122 entre 181 países. Bogotá, sólo contaba con 1.8 camas hospitalarias por mil habitantes (DNP, 2018). ${ }^{13}$ En cuanto al gasto en salud, Colombia, con 960 dólares per cápita al año estaba en el puesto 43 de 46 países de la OCDE y Chile, con 2.182 dólares per cápita, en el puesto 35, comparados con Estados Unidos, Suiza y Noruega que tienen los mayores gastos de la comunidad de países desarrollados, con $10.586,7.317$ y 6.187 dólares per cápita respectivamente. Con relación al PIB, Chile gastaba 8.9 por ciento en salud y Colombia 7.2 por ciento, frente a 16.9 por ciento de Estados Unidos, 12.2 por ciento de Suiza y 11.2 por ciento de Alemania. En personal de salud, Colombia contaba con sólo 2.2 médicos por mil habitantes, lo que lo ubicaba en el puesto 32 de 36 países de la OCDE, y Chile, 2.6 médicos por mil habitantes frente a Austria con 5.2 médicos por mil habitantes y Noruega, con 4.9. Asimismo, Colombia ocupaba el penúltimo lugar de la OCDE con sólo 1.3 enfermeras por mil habitantes. ${ }^{14}$

Otros indicadores, de los que no se tienen registros sistematizados, dan cuenta de faltantes injustificados de infraestructura y dotación. En Colombia, al momento de iniciarse la pandemia se contaba con sólo un laboratorio público, el del Instituto Nacional de Salud, con capacidad certificada para procesar muestras de Covid-19. Le tomó cinco meses al gobierno para habilitar un número razonable de laboratorios entre los de universidades y privados. Se enfrentaron obstáculos burocráticos de todo tipo que afectaron por ejemplo las importaciones de equipos automatizados para procesar las pruebas, y la importación de los reactivos necesarios. ${ }^{15} \mathrm{~A}$ principios de agosto de 2020 se llegó en Colombia a una capacidad de 43 mil pruebas diarias en todo el país (Dinero, 2020), pero en ese mes, se habían acumulado sólo 37 pruebas por mil habitantes; la situación de Chile en este sentido, era bastante mejor, 97 pruebas por mil habitantes pero aún lejos de la experiencia de otros países: Luxemburgo 707, Emiratos Árabes, 505, Dinamarca, 297 e Islandia, 229 pruebas por mil habitantes respectivamente (E1 Tiempo, 2020).

\footnotetext{
${ }^{13}$ No se cuenta con datos comparables en cuanto al estado de las UCI. En Colombia, en marzo de 2020 se contaba sólo con 5,271 de estas unidades en todo el país, y no todas dotadas con ventiladores mecánicos; además, estaban concentradas en las grandes ciudades. Varios departamentos no contaban en ese momento con una sola cama de cuidados críticos (García, Francy et al., 2020) ${ }_{14}^{14}$ No está disponible el dato de enfermeras por mil habitantes para Chile.

${ }^{15}$ No se tienen reportes confiables de la cantidad de pruebas realizadas. Según reportes de la prensa, en varios momentos hubo miles de resultados de pruebas represados. Las aseguradoras privadas EPS no respondieron ante la demanda e incluso fueron objeto de requerimiento por la Contraloría General de la República ante las demoras para entregar los resultados de las pruebas (RCN, 2020a) y en su momento llegaron a contabilizarse más de 30000 muestras inutilizadas por mala identificación o falta de protocolos de manejo (Infobae, 2020).
} 
Todos los indicadores citados corroboran que la implantación en Colombia y Chile de sistemas de salud de corte neoliberal basados en el mercado de aseguramiento privado, condujo al desmantelamiento de la capacidad para atender objetivos de salud pública como los que demandaba la pandemia. De allí que los gobiernos tuvieran que realizar, a marchas forzadas, grandes inversiones para tratar de colocar la capacidad de los sistemas al nivel requerido por la pandemia, lo cual, en aspectos cruciales como en la capacidad de hacer pruebas y rastreo de contagios, simplemente no fue posible. Esto explica por qué el gobierno, al menos en el caso de Colombia finalmente haya desistido por completo de aplicar estas estrategias desde el ámbito de la salud para luchar contra la pandemia. Sorprendentemente en el caso de Colombia, las mencionadas inversiones corrieron a cargo del Estado, es decir a cargo de los impuestos y por lo tanto de los bolsillos de los ciudadanos, ya que no fueron atendidas por los intermediarios privados de la salud que durante tanto tiempo se han lucrado del sistema privatizado.

La desestructuración producida por el neoliberalismo en los sistemas de salud se tradujo en una reducción de la capacidad de los estados para garantizar el derecho a la salud que se consagra en las constituciones políticas nacionales. Contrario a la garantía del derecho a la salud, el funcionamiento ha exacerbado la desigualdad en el acceso efectivo a los servicios, en detrimento de la población de menores recursos y de las divisiones territoriales diferentes de las grandes ciudades. En los pocos balances disponibles sobre el acceso efectivo y la calidad de los servicios, los indicadores conducen a pensar que la desatención en salud es alta, pero sobre todo, desigual. En el caso de Colombia, Guerrero et al. (2010: 150), señala que de las 1.219 entidades prestadoras de salud IPS registradas en el sistema, sólo 19 (1.5 por ciento) cumplían con estándares altos de garantía de calidad. García et al. (2020: 9) llaman la atención sobre la desigualdad en el desarrollo de la infraestructura requerida para la atención de los pacientes más graves en las regiones más apartadas del país, donde se concentran grupos poblacionales especialmente vulnerables. Detectan graves carencias de equipos biomédicos y escaso talento humano capacitado, el cual enfrenta contratación laboral lesiva y discontinua, pagos atrasados, mientras persisten prácticas corruptas en la gestión de los recursos destinados para la atención de la pandemia. Otro indicio de las carencias de atención es lo que se ha llamado la judicialización de los sistemas de salud. Tanto en el caso de Chile como en Colombia, muchas personas deben acudir a los estrados judiciales para hacer valer su derecho a recibir atención. 
En este contexto, y aunque aún no hay estudios a fondo al respecto, existen indicios de que las medidas implementadas por la pandemia están generando retrasos en la atención oportuna de pacientes con otras condiciones distintas al Covid-19 (García et al., 2020: 9). Es fácil prever que los efectos en otras enfermedades van a ser "devastadores" como lo registra un documento de la OPS (AFP, 2020: 1). Basado en una encuesta a 27 países, este organismo detectó la suspensión de campañas de vacunación de rutina, problemas para la atención de embarazos y dolencias no transmisibles, como la hipertensión y la diabetes, así como la escasez de medicamentos para tratar el VIH y la tuberculosis. La preocupación de varios observadores se extiende también a los posibles efectos en la salud mental, el suicidio, la violencia basada en género y la desnutrición de menores de cinco años. En Colombia, una estrategia principal frente al Covid-19, ampliamente promocionada por el gobierno y por las EPS en los diferentes medios es "quedarse en casa", estrategia muy conveniente para las aseguradoras privadas que se ahorran muchos recursos en la atención, pero que seguramente irá en detrimento de la atención de las enfermedades diferentes al Covid 19.

\section{Los determinantes sociales de la salud y el impacto de la pandemia}

Los determinantes sociales de la salud son las circunstancias presentes en el transcurso vital de las personas, incluyendo el sistema de salud que las cubre. Estos determinantes explican las inequidades sanitarias, es decir las diferencias injustas y evitables observadas en la situación sanitaria entre los países (OMS, 2020). En América Latina, la desigualdad, la pobreza y la informalidad son determinantes principales de las inequidades de acceso a la salud. Los impactos negativos de la pandemia pueden verse ampliamente potenciados por tal contexto (Acosta et al., 2020).

A través de su larga vigencia en la región, el modelo neoliberal no ha permitido que haya una mejora notoria en la equidad. En el caso de Colombia, el índice de Gini del ingreso per cápita sólo se modificó levemente, de 0.573 a 0.571 en el periodo 2002 a 2018, y aunque en Chile se logró reducir dicho índice de 0.50 a 0.45 en el mismo periodo, estos dos países se ubican como el segundo y tercero con mayor desigualdad en la distribución del ingreso en la región, sólo por detrás de Brasil (Universidad de los Andes, 2020a: 1-2; The New York Times, 2020: 1-8). 
Asimismo, y a pesar de que las estadísticas reportan reducción en los niveles de pobreza por ingreso ${ }^{16}$, las tasas de carencias de los hogares continúan siendo muy elevadas, aún en los centros urbanos de mayor "desarro1lo" de los países como lo muestran los indicadores del Índice de Pobreza Multidimensional (IPM). En el caso de Santiago de Chile, de acuerdo con los datos de la Encuesta CASEN de 2017, ${ }^{17} 17.6$ por ciento de la población se clasificaba como pobre multidimensional. En el caso de Bogotá, según los datos de la Encuesta Multipropósito (EMP) de 2017, ${ }^{18}$ el IPM agregado afectaba a 4.7 por ciento de los hogares, ${ }^{19}$ pero este indicador puede estar subestimado ${ }^{20}$ ya que la misma encuesta registra que 46.7 por ciento de los hogares de la ciudad pertenecen a los estratos 1 y 2 , los de mayor pobreza. Aun así, examinando las regresiones de los datos de las mismas encuestas, desagregados a nivel de las divisiones territoriales menores en las dos ciudades,$^{21}$ se puede comprobar una clara relación positiva entre las tasas de contagio y de muerte por Covid-19 y los índices agregados de pobreza multidimensional (Figura 1). Por otro lado, la descomposición del IPM en sus indicadores parciales muestra una realidad más acuciante de pobreza en las dos ciudades: 28.2 y el 21.9 por ciento de los hogares están afectados por carencias en educación ${ }^{22}$ en Santiago de Chile y en Bogotá respectivamente; el hacinamiento afecta a 21.7 por ciento de los hogares de Bogotá; y las carencias en aseguramiento (adscripción) o acceso (atención) al sistema de salud afectan a 15 por ciento de los hogares en Bogotá y a 12.5 por ciento en Santiago de Chile. Como se verá enseguida, junto con la informalidad, estas son las carencias que más se asocian con los impactos de la pandemia.

${ }^{16}$ En Colombia, la pobreza monetaria se redujo de 49.7 por ciento en 2002 a 27 por ciento en 2018.

17 Bases datos de la encuesta CASEN de 2017, obtenidas del Ministerio de Desarrollo Social (2017), procesadas por los autores.

18 Las bases de datos de la Encuesta Multipropósito de Bogotá (EPM) de 2017, fueron obtenidas del DANE (2018).

19 Las definiciones de los índices de Pobreza Multidimensional (IPM) para los dos países difieren en las dimensiones incluidas y en las ponderaciones y por tanto no son estrictamente comparables.

20 En Bogotá, se reportan como pobres por IPM los hogares que tengan al menos 33 por ciento de las carencias. Si se contabilizaran los hogares que tienen al menos 20 por ciento de las carencias, el índice sería de 28.4 por ciento.

21 Un total de 19 localidades urbanas en Bogotá y 52 Comunas en Santiago de Chile.

22 En Santiago de Chile esta carencia se refiere a los hogares en que al menos uno de sus integrantes, mayores de 18 años, ha alcanzado menos años de escolaridad que los establecidos por la Ley de acuerdo a su edad (12 años). En Bogotá, se refiere a los hogares en que alguno de los miembros mayores de 17 años ha alcanzado menos de nueve años de educación. 
Figura 1: Bogotá y Santiago, asociación de la pobreza multidimensional con las tasas acumuladas de contagios y fallecimientos por localidades

Bogotá

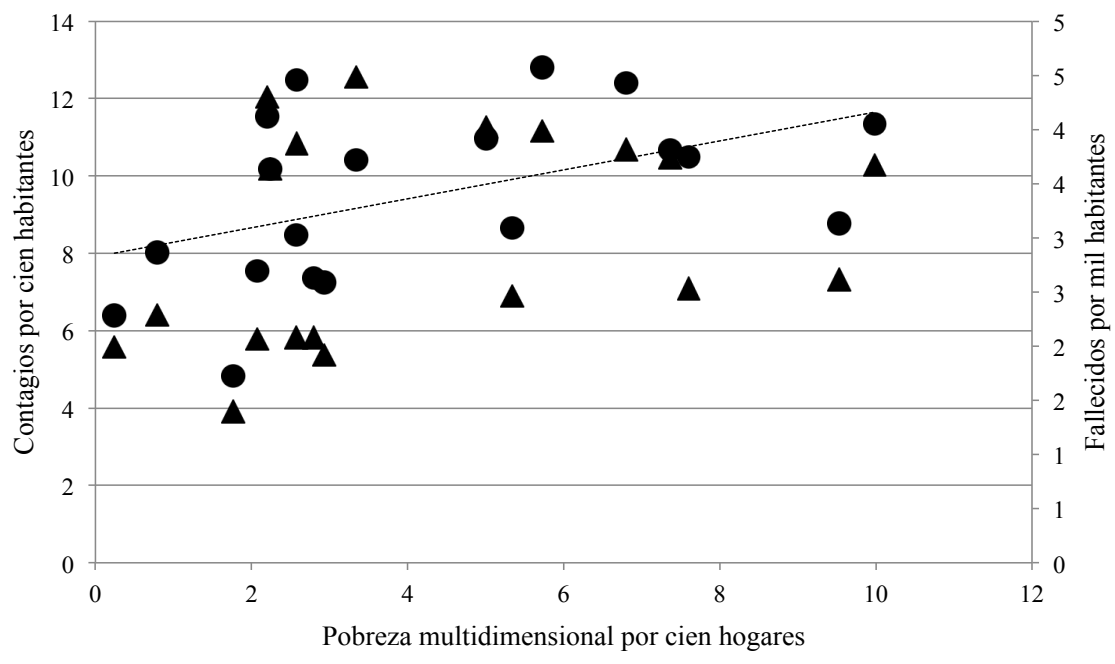

- Contagios por cien habitantes

$\Delta$ Fallecidos por mil habitantes

Fuente: DANE, Encuesta Multipropósito de Bogotá, 2017; INS, Estadísticas Covid-19.

Santiago de Chile

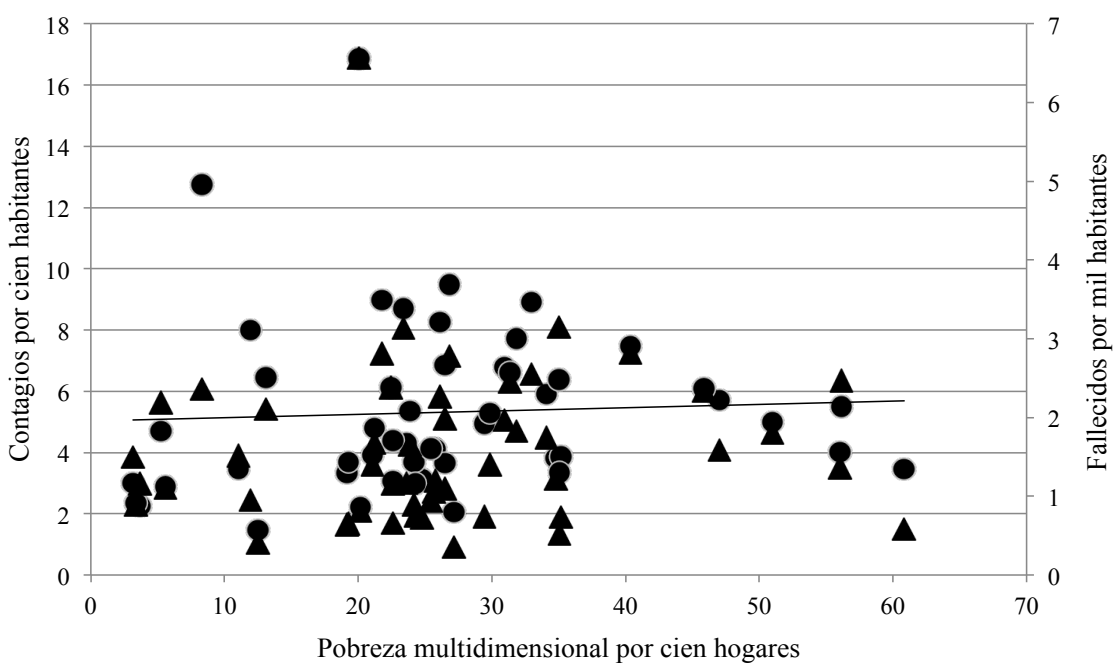

- Contagios por cien habitantes

$\Delta$ Fallecidos por mil habitantes

Fuente: Ministerio de Desarrollo Social. Encuesta CASEN 2017. 
El avance de la pandemia ha demostrado que la población pobre está sometida a tasas mayores de contagio y de muerte por Covid-19, mayor susceptibilidad que se presenta en función de su situación desfavorable en cuanto a los determinantes sociales de la salud. Entre estos determinantes se destacan, por su impacto específico sobre la pandemia, la informalidad del empleo, las barreras de acceso a los servicios de salud, las carencias en educación y el hacinamiento, entre otras. En lo que sigue se verifica la estrecha relación entre las condiciones de la población pobre en cada uno de estos factores y los mayores impactos de la pandemia.

La informalidad del empleo (y de la economía, en general) es un reconocido daño del modelo neoliberal con gran impacto en América Latina, y que no sólo contribuye de manera directa al agravamiento de la pandemia, sino que también menoscaba la capacidad de los gobiernos para adoptar estrategias efectivas para el combate contra ella. Según las cifras oficiales, en Colombia el porcentaje de empleo informal antes de la pandemia, era de 47.6 por ciento $^{23}$ en el promedio de las 13 principales ciudades del país (RCN, 2020b), pero según el Observatorio Laboral de la Universidad del Rosario (2018: 1), la informalidad era de 60 por ciento para el total del país. En todo caso, se trata de una masa muy amplia de población que realiza sus actividades en la calle y depende de los ingresos del día a día para subsistir. Para el caso de Bogotá, la EMP de 2017 indica que la carencia de mayor peso dentro de las dimensiones consideradas en el Índice de Pobreza Multidimensional es la de la informalidad, que afecta a 41 por ciento de los hogares pobres de la ciudad. En el caso de la Región Metropolitana de Santiago de Chile, la incidencia de la informalidad es un poco menor, pero también configura un gran daño como legado del neoliberalismo: en el primer trimestre de 2020, la informalidad afectaba a 27.2 por ciento de la población ocupada. ${ }^{24}$

La relación entre las diferentes dimensiones de la pobreza y el impacto de la pandemia en la población pobre, se constata usando los datos de la EMP 2017 de Bogotá y la CASEN 2017 en Santiago, desagregados por divisiones menores, y puestos en relación con los datos, también desagregados a ese mismo nivel, de contagios y de muertes acumuladas por la pandemia, provenientes de las estadísticas oficiales. ${ }^{25}$ Como se ha señalado, la informalidad es un factor muy importante para explicar el mayor impacto

${ }^{23}$ El DANE clasifica como informales a los trabajadores no afiliados a la Seguridad Social (DANE, 2020: 24).

${ }_{24}$ Datos de la Encuesta Nacional de Empleo, INE, Chile.

25 Datos del Instituto Nacional de Salud (INS, 2020) en el caso de Bogotá y de la mesa Covid-19 del Ministerio de Ciencias en el caso de Santiago de Chile. 
de la pandemia en la población pobre. En efecto, en el caso de Bogotá, se comprueba una relación positiva entre los porcentajes de pobreza por informalidad y las tasas de contagio y de muertes con correlaciones de 65 y 62 por ciento respectivamente (Figura 2) ${ }^{26}$ No obstante, el impacto de la informalidad en la pandemia va mucho más allá del aumento de las tasas de contagio y de muerte. De hecho, la informalidad se convierte prácticamente en el impedimento principal para que los gobiernos apliquen políticas efectivas para reducir la progresión de la pandemia.

Figura 2: Bogotá, asociación del trabajo informal en los hogares, con las tasas acumuladas de contagios y fallecimientos por localidades

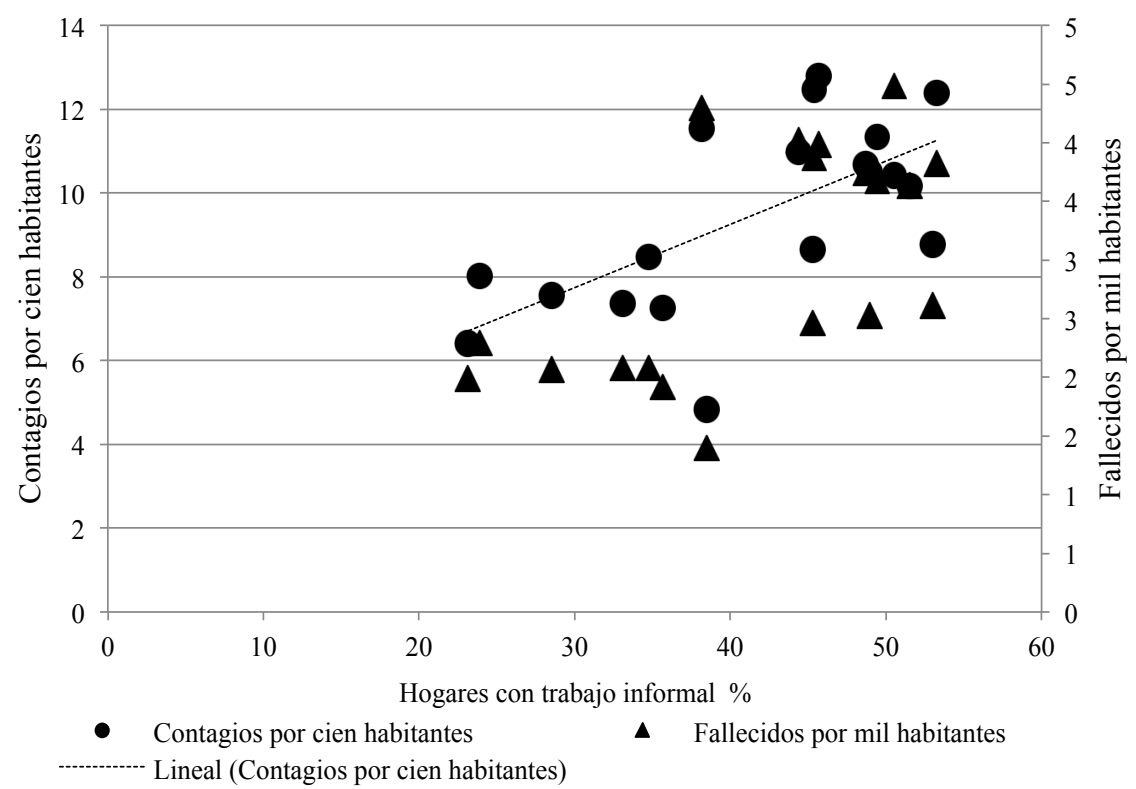

Fuente: DANE, Encuesta Multipropósito de Bogotá, 2017; INS, Estadísticas Covid-19.

En los países de América Latina, la medida principal adoptada por los gobiernos ha sido el confinamiento y se ha observado que en los periodos en que se han establecido cuarentenas estrictas se ha logrado reducir la tasa de reproducción del virus (El País, 2020). Sin embargo, la altísima informalidad, junto con la falta de mecanismos o fondos preestablecidos de emergencia (tales como el subsidio de desempleo que existe en países desarrollados) no permiten mantener las restricciones a la movilidad de la población de manera continuada. Esto es así porque las personas en situa-

${ }^{26}$ No se contó con estadísticas de informalidad por comunas para el caso de Santiago de Chile. 
ción de informalidad se enfrentan con la disyuntiva de protegerse contra la pandemia o protegerse y proteger a sus familias del hambre. En esa circunstancia es muy difícil que una persona esté en disposición de acatar medidas de confinamiento. Más aún cuando los gobiernos determinan sucesivas excepciones a las restricciones obedeciendo no sólo al carácter indispensable de algunos servicios sino también a diferentes conveniencias políticas y económicas, estimulando de esa manera toda clase de fraudes y elusiones. De hecho, información disponible en Bogotá sobre los "comparendos" o "partes" impuestos por la policía a la población que incumple las restricciones sanitarias, indican que los trabajadores informales son quienes más violan las restricciones y que, además, reinciden en esas conductas. Lo cierto es que al final, los días efectivos de cuarentena en el caso de los trabajadores informales terminan siendo prácticamente nulos. La situación es de tal magnitud que de acuerdo con el informe ya mencionado de $E l$ Pais (2020), puede decirse que la informalidad ha anulado la capacidad de los países para tomar medidas efectivas en la lucha contra la pandemia y es una de las razones por las cuales las medidas de confinamiento en América Latina están entre las más largas del mundo, pero han sido inefectivas, o al menos no han logrado suprimir el contagio a los niveles que sí se logró en Europa.

Ante la demostrada falta de sostenibilidad de las estrategias de confinamiento obligatorio, los gobiernos de estos países deberían haber reforzado las medidas epidemiológicas, a saber, pruebas diagnósticas a tiempo, rastreo de contactos y aislamientos individualizados de casos sospechosos, estrategias que dieron resultado en Europa y Asia (El País, 2020). Sin embargo, como se ha señalado, al llegar la pandemia quedaron en evidencia las grandes dificultades para implementar este tipo de medidas, debido al desmantelamiento de los sistemas de salud que habían producido las reformas neoliberales. También queda en evidencia otro gran daño del neoliberalismo, la creación de sistemas duales de salud que ejercen una fuerte discriminación de la población pobre en el acceso a servicios de calidad.

A pesar de que se ha resaltado repetidamente el incremento del aseguramiento como el logro principal de las reformas de la salud en Chile y Colombia, los datos indican que persisten carencias importantes al respecto. Como ya se ha señalado, en Bogotá, la carencia de aseguramiento o de atención en salud afecta a más de 15 por ciento de los hogares y en Santiago de Chile a 12.5 por ciento de los hogares. Los datos por comunas de Bogotá permiten comprobar que las carencias de aseguramiento y atención en salud afectan principalmente a la población pobre y, además, que tales 
carencias se relacionan de manera directa (correlaciones de 57 y 59 por ciento, respectivamente) con las tasas de contagio y muerte producidas por la pandemia (Figura 3). En el caso de Santiago de Chile las correlaciones son bastante menores ${ }^{27}$ pero también son positivas.

Las carencias en educación son otra característica de los hogares pobres que se relaciona claramente con la prevalencia de la pandemia. Como ya se ha señalado, en Santiago de Chile, 28 por ciento y en Bogotá 22 por ciento de los hogares pobres tienen carencias en logro educativo. En Bogotá, la correlación de esta carencia con las tasas acumuladas de contagio y de muerte por la pandemia son altas: 60 y 46 por ciento respectivamente (Figura 4, panel a). En esta ciudad, además, todas las dimensiones del IPM que tienen que ver con carencias en educación (analfabetismo, inasistencia y rezago escolar) se relacionan positivamente con las tasas acumuladas de contagios y de muertes. El analfabetismo, aunque afecta a un número pequeño de hogares, presenta correlaciones altas, de 54 y 41 por ciento, con las tasas de contagio y de muertes respectivamente (Figura. 4, panel b). Lo que puede deducirse es que la falta de acceso a la información y la baja capacidad de comprensión de mensajes es otro de los mecanismos por los cuales la pandemia se afinca preferentemente en la población pobre. Está por demás resaltar que la falta de educación es otro de los grandes daños del neoliberalismo en estos países, donde la educación es privatizada y altamente segmentada. El panorama de carencias educativas configura en los hogares pobres lo que se ha llamado una "trampa cognitiva" (Universidad de los Andes, 2020b: 1-2) en referencia a este contexto en el que se suman una escasa disponibilidad de información de calidad, bajas expectativas de las personas, percepción de invulnerabilidad y percepción de incumplimiento por parte de "los otros". Todo esto se da en un ambiente en el que la profusión de mensajes contradictorios y campañas de desinformación dificultan el discernimiento sobre las conductas adecuadas a seguir.

El hacinamiento en que debe vivir la población pobre es otro factor que influye de manera apreciable en los impactos de la pandemia. En estudios de la Universidad Externado Colombia (Universidad Externado, 2020: 1-2) se ha observado que en las viviendas de interés social o prioritario, ${ }^{28}$ la probabilidad de contagio ha sido ocho veces mayor que la de otros estratos.

27 Correlaciones de 24 y 22 por ciento, respectivamente, entre los porcentajes de no adscripción a los servicios de salud y los porcentajes de contagios y de muertes.

28 Viviendas subsidiadas, por lo general pequeñas (unos $50 \mathrm{~m}^{2}$ ) y usualmente hacinadas, con seis personas o más. 
Daño social, neoliberalismo y la pandemia del Covid-19 en América Latina / C. MARTíNEZ GÓMEZ y C. PARRAGUEz CAMUS

Figura 3: Bogotá y Santiago, asociación del aseguramiento en salud con las tasas acumuladas de contagios y fallecimientos por localidades

\section{Bogotá}

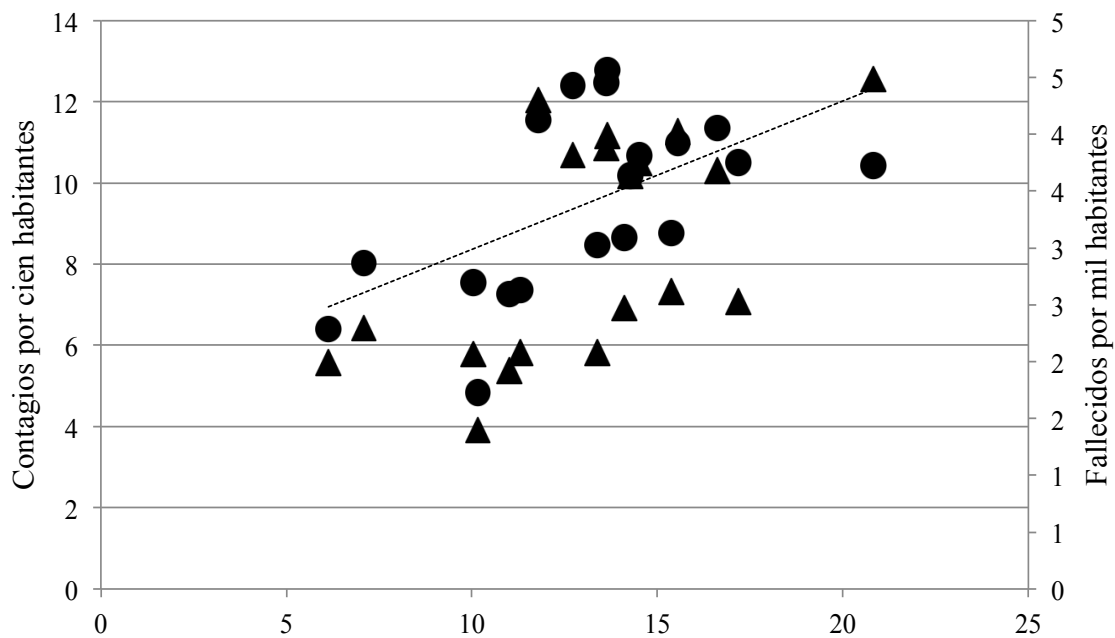

Carencia en Aseguramiento de salud por cien hogares

- Contagios por cien habitantes

\ Fallecidos por mil habitantes

Lineal (Contagios por cien habitantes)

Fuente: DANE, Encuesta Multipropósito de Bogotá, 2017; INS, Estadísticas Covid-19.

Santiago de Chile

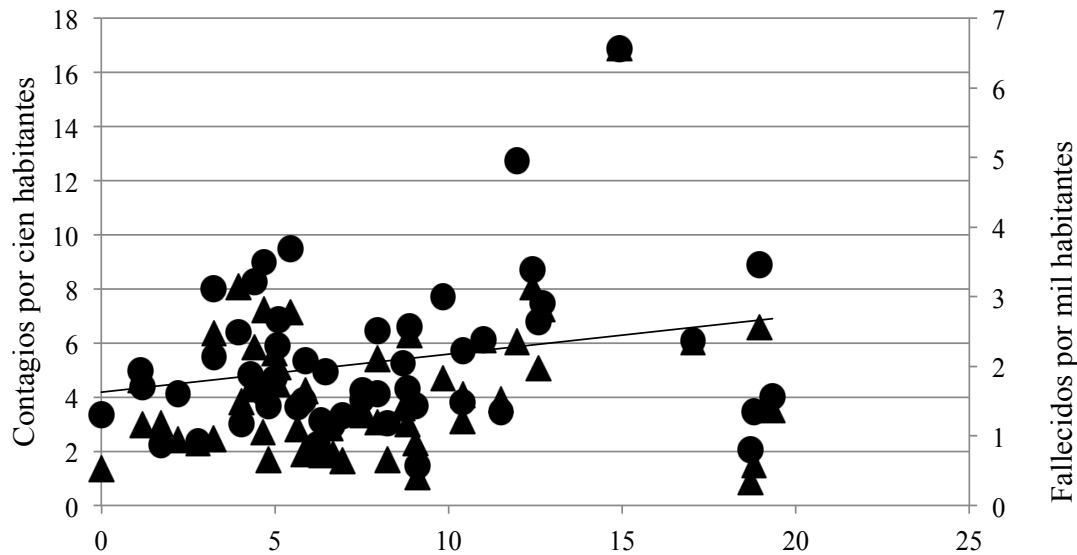

Carencia en aseguramiento de salud por cien hogares

- Contagios por cien habitantes

$\Delta \quad$ Fallecidos por mil habitantes

Fuente: Ministerio de Desarrollo Social. Encuesta CASEN 2017. 
Figura 4: Bogotá, asociación de las carencias en educación con las tasas acumuladas de contagios y fallecimientos por localidades

\section{Carencia en logro educativo}

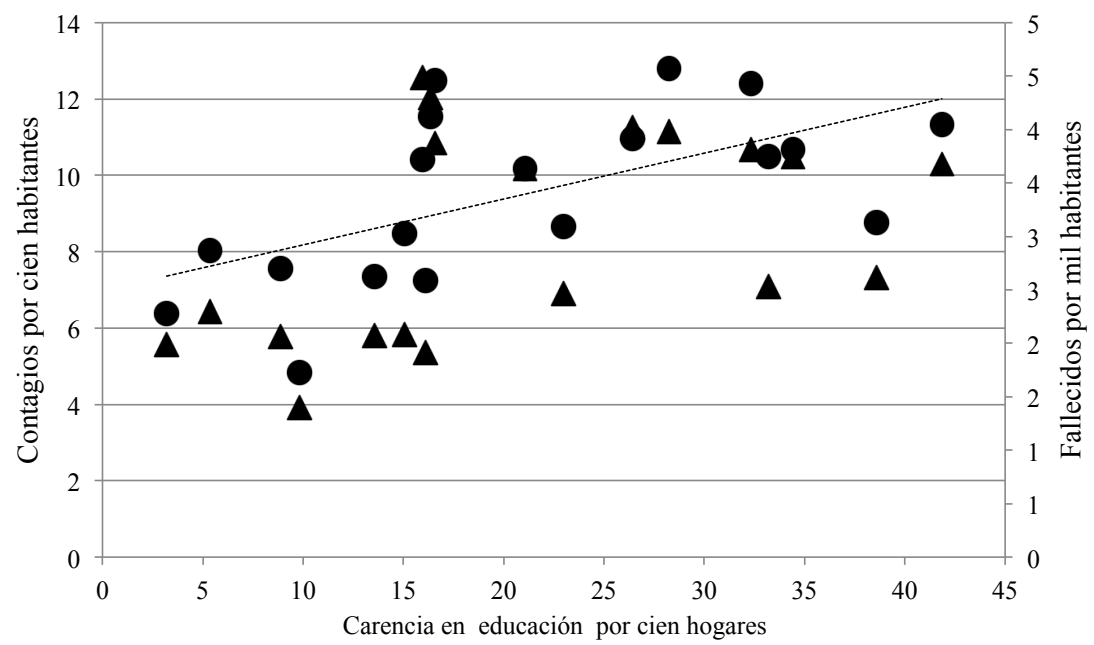

- Contagios por cien habitantes

\ Fallecidos por mil habitantes

Lineal (Contagios por cien habitantes)

Fuente: DANE, Encuesta Multipropósito de Bogotá, 2017; INS, Estadísticas de Covid-19.

\section{Analfabetismo}

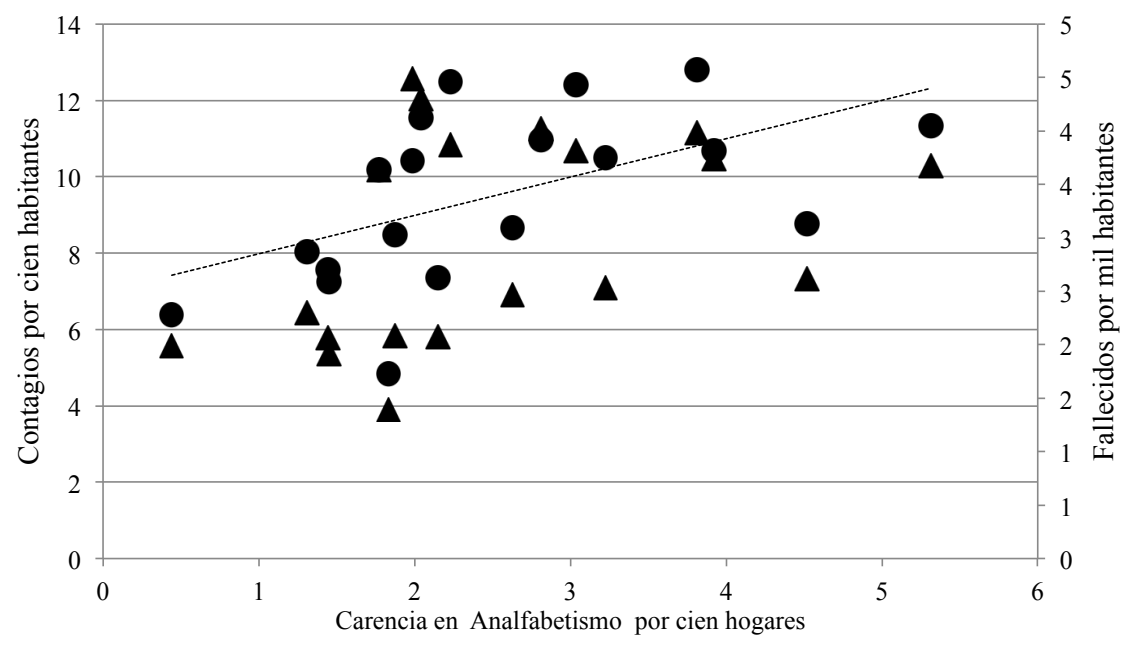

- Contagios por cien habitantes

\ Fallecidos por mil habitantes

Lineal (Contagios por cien habitantes)

Fuente: DANE, Encuesta Multipropósito de Bogotá, 2017; INS, Estadísticas de Covid-19. 
Asimismo, se ha verificado que la mayor densidad poblacional de los entornos donde residen los pobres favorece una mayor intensidad de los contactos fortuitos u obligatorios, llevando a mayores tasas de contagio, como en efecto sucede en Bogotá en barrios donde la densidad poblacional está entre 333 y 581 habitantes por hectárea ${ }^{29}$ (Universidad Externado de Colombia, 2020: 2-3). De acuerdo con los datos de la EMP el 21 por ciento de los hogares de Bogotá pueden considerarse hacinados (tres o más personas por cuarto), y esta situación de los hogares se correlaciona significativamente con las tasas de contagio y de muerte con correlaciones de 50 y 34 por ciento respectivamente (Figura 5). En Santiago de Chile, aunque el hacinamiento de los hogares tiene menor prevalencia que en Bogotá, ${ }^{30}$ las correlaciones del hacinamiento crítico con las tasas acumuladas de contagio y de muerte son las mayores observadas en esta ciudad 51 y 55 por ciento, respectivamente. ${ }^{31}$

Otras dimensiones del entorno y condiciones de las viviendas de la población pobre también se correlacionan de manera positiva, aunque en menor grado con el impacto de la pandemia. Entre ellas conviene destacar la carencia de conexión a acueducto, por su estrecha relación con las normas de higiene que deben ser adoptadas para protección contra la pandemia. Es claro que no puede esperarse que dichas normas se cumplan en zonas rurales, zonas marginales o barrios pobres donde no se cuenta con conexión a acueducto o donde, como es frecuente, aunque se tiene la conexión, el servicio efectivo es irregular, intermitente o nulo. Según la Universidad Externado de Colombia (2020: 1), en este país aún existe un número elevado de personas que no tienen acceso a agua potable; se estiman aproximadamente 1.6 millones de personas de cabeceras municipales y seis millones de personas de áreas rurales sin acceso a acueducto. En el caso de Bogotá, las estadísticas recogen un número pequeño de hogares sin conexión a acueducto (poco menos de dos mil hogares según la EMP 2017), pero a pesar de la baja frecuencia, la falta de conexión a acueducto se correlaciona positivamente con las tasas de contagio y de muerte por la pandemia. Por otro lado, como se ha dicho, que el hogar disponga de la conexión no garantiza la continuidad y calidad del servicio, con lo que la asociación real con este factor puede ser bastante mayor.

\footnotetext{
29 Patio Bonito y Corabastos, el Rincón y Tibabuyes, Bosa Occidental y Diana Turbay, el Minuto de Dios, Alfonso López y San Francisco.

30 En Bogotá la carencia por hacinamiento se mide con base en 3 o más personas por cuarto.

${ }^{31}$ En los datos de Santiago de Chile se diferencia entre hacinamiento medio, de 3.5 a 4.9 personas por cuarto y hacinamiento crítico, de cinco o más personas por cuarto.
} 
Figura 5: Bogotá y Santiago, asociación del hacinamiento de los hogares con las tasas acumuladas de contagios y fallecimientos por localidades

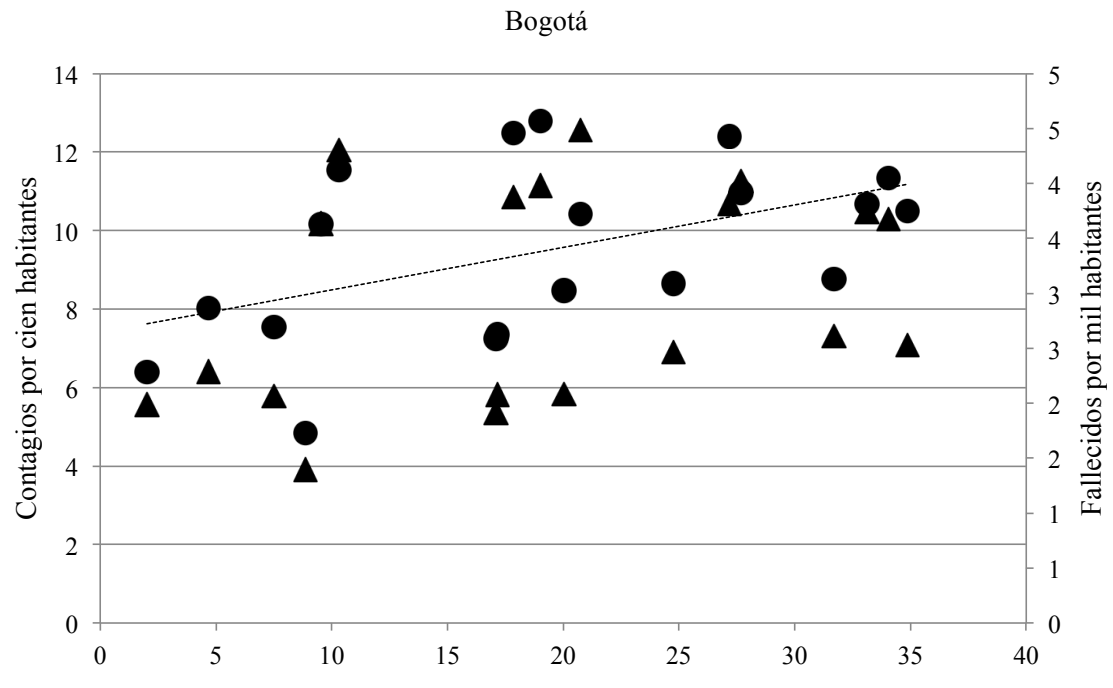

Hogares con hacinamiento por cien

- Contagios por cien habitantes

\ Fallecidos por mil habitantes

Lineal (Contagios por cien habitantes)

Fuente: DANE, Encuesta Multipropósito de Bogotá, 2017; INS, Estadísticas de Covid-19.

Santiago de Chile

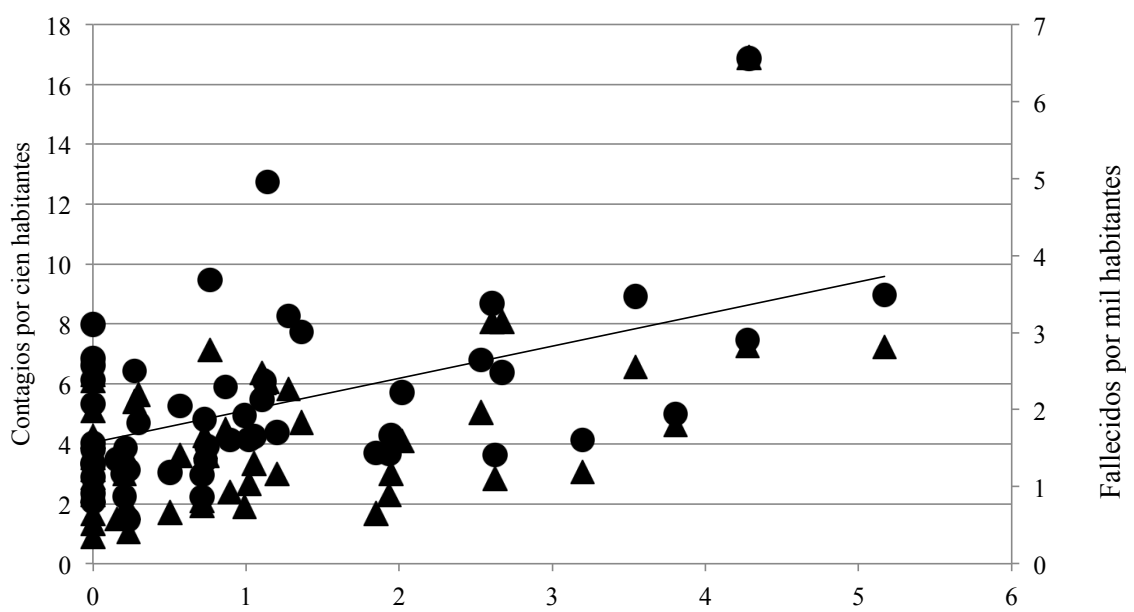

Hogares con hacinamiento crítico por cien

- Contagios por cien habitantes

\ Fallecidos por mil habitantes Lineal (Contagios por cien habitantes)

Fuente: Ministerio de Desarrollo Social. Encuesta CASEN 2017. 
En resumen, los datos disponibles han permitido comprobar el efecto directo e importante de la inequidad y la pobreza sobre el impacto de la pandemia en la población. Las diferentes dimensiones de la pobreza multidimensional aportan ilustración sobre los mecanismos a través de los cuales actúa dicha relación. La informalidad de las actividades es quizás el mecanismo más determinante, $y$, dado que a su vez representa un reconocido daño del neoliberalismo a la economía y la sociedad de América Latina, permite establecer la relación entre los daños de este modelo y la vulnerabilidad de la región a la pandemia, además que explica también la incapacidad de los gobiernos para adoptar política efectivas y sostenibles contra este flagelo. En ese mismo sentido se han obtenido evidencias de cómo el daño del neoliberalismo, que actúa a través del encarecimiento y segmentación del acceso al sistema educativo, a la salud, a la vivienda y a los servicios esenciales, ha colocado a la población de América Latina en una posición de máxima vulnerabilidad a la pandemia.

\section{CONCLUSIONES Y RECOMENDACIONES}

La pandemia deja al descubierto daños sociales estructurales en la región. Las altas correlaciones entre contagios y muertes que generan daños físicos a la población muestran sus fuertes correlaciones con los daños autonómicos tales como las carencias en educación, exclusión del mercado laboral (informalidad), así como daños relacionales de desigualdad territorial e inequidad. Por una parte, esto prueba la sistematicidad de los daños en sociedades neoliberales, pero por otra, retrata también que las trabas impuestas al florecimiento humano no serían ni casuales ni aisladas. Responden a una transversalidad de las políticas fraguadas en la región que superarían con creces la casuística de la responsabilidad individual.

Utilizando datos de Bogotá y Santiago desagregados espacialmente, se ha podido comprobar la gran desigualdad de la población en cuanto a los determinantes sociales de la salud y la estrecha relación de estos determinantes con los impactos de la pandemia. Se encuentra que en estas ciudades la informalidad de las actividades es el determinante más importante del impacto diferencial de la pandemia. La informalidad, además, explica en gran parte la falta de sostenibilidad de políticas de lucha contra la pandemia, como las restricciones a la movilidad, que debieron ser truncadas tempranamente. Se encuentran también relaciones relevantes con los problemas de acceso a los servicios de salud, las carencias en educación, el hacinamiento y el acceso a agua potable. Se desprende la necesidad de un manejo integral de las medidas dirigidas a la población pobre y los traba- 
jadores informales, que incluya subsidios, renta básica, ayudas en especie, alivios financieros, y otras medidas suficientes y sostenidas, sin las cuales no se puede esperar el acatamiento de medidas restrictivas, y por el contrario se generan riesgos adicionales de empobrecimiento y ampliación de las brechas sociales.

La educación y el acceso a información oportuna y de calidad también han quedado al debe tras la pandemia. Las altas correlaciones entre muertes y contagios por Covid-19 con los niveles educativos demuestran que reformas en el sentido de garantizar el acceso y calidad en educación deben avanzar hacia esquemas más colectivos y menos segregados territorial y socialmente.

Conexiones por describir dicen relación, por ejemplo, con las tasas de endeudamiento de los hogares por concepto de salud y sus vínculos y consecuencias con la informalidad del empleo. La dicotomía que enfrentan los trabajadores informales entre cuidarse de la enfermedad o comer, pareciera superarse desde la estrategia de supervivencia del día a día, lo que deja la interrogante de como ellos enfrentarán los niveles de endeudamiento en salud post contagio.

Los indicadores que dan cuenta del retroceso de la pobreza en la región deben repensarse. De la mano de la informalidad, la epidemia sacó a la luz situaciones de marginalidad y exclusión social probablemente subestimadas. En este sentido, nuevas metodologías y procedimientos deberían evaluarse para medir y dimensionar los impactos de la informalidad en la estructuración de daños sociales. Los niveles de informalidad parecen sobrepasar las previsiones actuales y desbordar las herramientas disponibles para focalizar el gasto, establecer subsidios y estrategias con oportunidad y equidad, ya que precisamente este grupo de la población se encuentra subestimado en las estadísticas.

La pandemia deja también como enseñanza a nivel latinoamericano la imperiosa necesidad de reformar profunda y estructuralmente nuestros sistemas de salud. Aquí será clave volver a retomar los objetivos de salud pública y revertir el traslado de la responsabilidad colectiva a la responsabilidad individual. Será importante así mantener la infraestructura pública ganada tras el Covid-19 (número de camas, equipamiento e insumos médicos, personal, etc.) y disponer de presupuestos permanentes de emergencia que sean capaces de gestionar con mayores niveles de equidad y solidaridad nuestros sistemas de protección social.

Con todo, una agenda de reducción de daños sociales es imperiosa para salir de esta crisis social y económica en la que nos encontramos. Por una 
parte, dicha agenda debe emerger desde la voluntad política y social de reformar nuestra forma de aproximarnos y hacer políticas públicas de cara al florecimiento humano. Pero, por otra parte, es indispensable para el éxito de la agenda, que las articulaciones ciudadanas que se dieron en Chile y Colombia en octubre y noviembre de 2019 vuelvan a escucharse. Los aires de reforma quedaron en pausa tras la llegada de la pandemia a América latina, pero quizás, y a la vista de los daños sociales dejados por el Covid-19 (y los anteriores a ella) pudieran retomarse a través de formas democráticas en las calles, en los escritorios de funcionarios de los gobiernos y en las urnas.

\section{REFERENCIAS BIBLIOGRÁFICAS}

Acosta, Enrique et al., 2020, En América Latina y el Caribe se debe actuar para mitigar los impactos negativos del COVID-19 sobre la población y la economía, marzo 26 de 2020, consultado en septiembre 2020, disponible en https://docs.google.com/forms/d/e/1FAIpQLSftO__B1q6PUrYsrId_uL9P9Ebq63wn0LdjjnihdP$07 \mathrm{gtY} 5 \mathrm{zQ} /$ viewform

AFP, 2020, Pandemia tiene "impacto devastador" en atención de otras enfermedades, advierte OPS, 4-08-2020, consultado en 4/08/2020, disponible en https:// www.france24.com/es/20200804-pandemia-tiene-impacto-devastador-en-atenci\%C3\%B3n-de-otras-enfermedades-advierte-ops.

Atria, Fernando, 2013, Veinte años después, neoliberalismo con rostro humano, Catalonia: Santiago de Chile.

Atria, Fernando, Larrain, Guillermo, Benavente, José, Couso, Javie, Joignant, Alfredo, 2013, El otro modelo: del orden neoliberal al régimen de lo público, Debate: Santiago de Chile.

CEPAL, 2010, Time for equality: closing gaps, opening trails, Comisión Económica para América Latina y el Caribe (CEPAL), Santiago de Chile.

CEPAL, 2019a, Panorama Social. Comisión Económica para América Latina y el Caribe (CEPAL), Santiago de Chile.

CEPAL, 2019b, Estudio económico de América Latina y el Caribe: el nuevo contexto financiero mundial efectos y mecanismo de transmisión en la región. Comisión Económica para América Latina y el Caribe (CEPAL), Santiago de Chile.

CEPAL, OPS, 2020, Salud y economía: una convergencia necesaria para enfrentar el COVID-19 y retomar la senda hacia el desarrollo sostenible en América Latina y el Caribe. Comisión Económica para América Latina y el Caribe (CEPAL), Organización Panamericana de Salud (OPS), Santiago de Chile.

DANE, 2018, Archivo Nacional de Datos ANDA, Encuesta Multipropósito de Bogotá EM 2017. Archivo de microdatos, Departamento Nacional de Estadística (DANE), consultado en agosto 2020, disponible en http://microdatos.dane.gov.co/ index.php/catalog/565/get_microdata 
DANE, 2020, Boletín Técnico Medida de Pobreza Multidimensional Municipal CNPV 2018, Departamento Nacional de Estadística (DANE), Bogotá, D. C. 31 de enero de 2020.

Dinero, 2020, Coronavirus: ¿cuántas pruebas procesa Colombia por día?, consultado el 6/08/2020, disponible en https://www.dinero.com/empresas/ confidencias-on-line/articulo/coronavirus-cuantas-pruebas-procesa-colombia-por-dia/295057.

DNP, 2018, Contexto institucional para las APP del sector salud en Bogotá. Departamento Nacional de Planeación (DNP), Bogotá, febrero 2018, consultado en agosto 2020, disponible en https://www.dnp.gov.co/programas/participaci\%C3\%B3n-privada-\%20y-en-proyectos-de-infraestructura/asociaciones-publico-privadas/Paginas/presentaciones.aspx

El PAÍS, España, 2020, Las cuarentenas infinitas de América Latina, 25-08-2020, consultado el 2/09/2020, disponible en https:/elpais.com/sociedad/2020-08-25/ las-cuarentenas-infinitas-de-america-latina.html_

El Tiempo, Colombia, 2020, Así va Colombia en pruebas para detectar Covid-19 (Datos del European Centre for Disease Prevention and Control). 13-08-2020, consultado el 2/09/2020, disponible en https://www.eltiempo.com/datos/pruebas-de-covid-en-colombia-comparadas-con-latinoamerica-y-el-mundo-528060

England, Kim, Ward, Kevin, 2016, “Theorizing neoliberalization”, en The Handbook of neoliberalism, 50-60 Routledge: New York.

Foucault, Michelle, 2002, Disciplina y Castigo. Siglo XXI editores Argentina: Buenos Aires.

García, Francy et al., 2020, "El derecho a la salud en tiempos de pandemia en Colombia: entre la inequidad endémica y el estado de emergencia", en Revista colombiana de bioética, Universidad El Bosque, Bogotá, julio.

Green, Duncan, 2003, "Poverty Brokers: The IMF and World Bank", en Silent revolution: the rise and crisis of market economics in Latin America, 39-71, Monthly Review Press: New York.

Guerrero, Ramiro, Gallego, Ana, Becerril, Víctor, Vásquez, Johana, 2011, “Sistema de salud de Colombia”, en Salud Pública, México.

Harvey, David, 2007, A brief history of neoliberalism. Oxford University Press: Oxford.

Hill, Douglas, Wald, Nave, Guiney, Tess, 2016, "Development and neoliberalism”, en The Handbook of neoliberalism, 130-141, Routledge: New York.

Hillyard, Paddy, Tombs, Steve, 2004, Beyond criminology? Taking harm seriously, Pluto press: London.

INE, 2020, Encuesta Nacional de Empleo, Instituto Nacional de Estadística (INE), Chile.

INFOBAE, 2020, La insólita razón por la que no pueden identificar a quien pertenecen más de 30.000 pruebas de coronavirus ya realizadas, 29-07-2020, 
consultado el 2/08/2020, disponible en https:/www.infobae.com/america/colombia/2020/07/29/colombia-la-insolita-razon-por-la-que-no-pueden-identificar-a-quien-pertenecen-mas-de-30-mil-pruebas-de-coronavirus-ya-realizadas/

INS, 2020, Boletines casos Covid-19, Colombia. Instituto Nacional de Salud de Colombia (INS), consultado en septiembre 2020, disponible en https://www.ins. gov.co/Paginas/Boletines-casos-COVID-19-Colombia.aspx

Lewis, Nick, 2016, "Governmentality at work in shaping a critical geographical politics", en The Handbook of neoliberalism, 73-83, Routledge: New York.

Lloyd-Sherlock, Peter, 2009, Social policy and inequality in Latin America: a review of recent trends, Social policy and Administration, julio, 43; 4; 22/10/2020. Disponible en https://onlinelibrary.wiley.com/doi/epdf/10.1111/j.1467-9515.2009 .00667.x

Mayol, Alberto, 2012, El derrumbe del modelo: La crisis de la economia de mercado en el Chile contemporaneo, LOM : Santiago de Chile.

Ministerio de Desarrollo Social Chile, 2017, Encuesta CASEN 2017, bases de datos.

Ministerio de Protección Social de Colombia, s/f, "Proyecto Evaluación y Reestructuración de los Procesos, Estrategias y Organismos Públicos y Privados encargados de adelantar las Funciones de Vigilancia y Control del Sistema de Salud. Informe Final, Capítulo 1", en Marco Conceptual de Análisis de los Sistemas de Salud. Bogotá.

Molina, Carlos, Giedion, Úrsula, Rueda, María, Alviar, Mauricio, 1994, El gasto público en salud y distribución de subsidios en Colombia. DNP, Bogotá.

Moulian, Tomas, 1998, El consumo me consume, LOM: Santiago de Chile.

Muggah, Robert y Aguirre, Katherine, 2018, Citizen security in Latin America: Facts and Figures, abril, 33; 06/10/2020. Disponible en https://igarape.org.br/ wp-content/uploads/2018/04/Citizen-Security-in-Latin-America-Facts-and-Figures.pdf

OCDE, 2020, Datos salud. Organización para la Cooperación y el Desarrollo Económico (OCDE), consultado 31-08- 2020, disponible en https://data.oecd.org/

OMS, 2020, Alocución de apertura del Director General de la OMS en la rueda de prensa sobre la Covid-19. Organización mundial de la salud (OMS), 11-03-2020, consultado en 20-08-2020, disponible en https://www.who.int/es/director-general/ speeches/detail/who-director-general-s-opening-remarks-at-the-media-briefingon-covid-19, 11-march-2020

OMS, 2021, Determinantes sociales de la salud, Organización Mundial de la Salud (OMS), consultado el 9/02/2021, disponible en: https:/www.who.int/social_ determinants/es/

OPS, 2020, Situación de Covid -19 en la región de las Américas. Organización Panamericana de la Salud (OPS), consultado el 15/10/2020, disponible en https:// www.paho.org/es/temas/coronavirus/brote-enfermedad-por-coronavirus-covid-19 
Parraguez, Carla, 2017, Evaluating the injuries of neoliberalism in Chile 19732015, Tesis de Doctorado, Universidad de Birmingham, Instituto de Ciencias sociales aplicadas

Peck, Jaime, 2010, "Neoliberal worlds", en Constructions of neoliberal reason, 1-38, Oxford University Press: Oxford.

Pemberton, Simon, 2016, Harmful societies: understanding social harm, Policy Press: Bristol.

Puello, José, 2015, "Neoliberalismo, anti neoliberalismo, nuevo neoliberalismo, episodios y trayectorias económico-políticas sudamericanas (1953-2015)", en Neoliberalismo en América Latina. Crisis, tendencias y alternativas, 19-42, CLACSO: Buenos Aires

RCN, 2020a, Anuncian acciones contra varias eps por demoras en resultados de pruebas. julio 25, Consultado en septiembre de 2020, disponible en https://www. rcnradio.com/colombia/anuncian-acciones-contra-varias-eps-por-demoras-en-resultados-de-pruebas

RCN, 2020b, Mas de cinco millones de colombianos están en la informalidad, 11/03/2020. consultado septiembre 2020. disponible en https://www.rcnradio. com/economia/mas-de-cinco-millones-de-colombianos-estan-en-la-informalidad-dane

Ruiz, Carlos, 2013, Conflictos sociales en el neoliberalismo avanzado analisis de clase de la revuelta estudiantil en Chile, CLACSO: Buenos Aires

Ruiz-Tagle, Jaime, 2017, Endeudamiento, sobre endeudamiento y buen uso de los créditos de hogares, Presentación Centro de micro datos departamento de economía universidad de Chile, octubre 2017, en Santiago de Chile. Disponible en:https://www.cepal.org/sites/default/files/document/files/jaime_ruiz-tagle.pdf

Santa María, Mauricio, García, Fabiana, Uribe, María José, 2009, Un diagnóstico general del sector salud en Colombia: Evolución, contexto y principales retos de un sistema en transformación. Disponible en http://www.med-informatica.net/ FMC_CMCB/VeeduriaCiudadana/CIDMEDvcacelapss/SaludRetosRegulacion MauricioSantamaria_cap1_final.pdf_

Solimano, Andres, 2015, Elites económicas, crisis y el capitalismo del siglo XXI, la alternativa de la democracia económica, Fondo de Cultura Economica: Santiago de Chile.

Springer, Simon, 2015, "Postneoliberalism?", en Review of Radical Political Economy, marzo, 47; consultado el 20/09/2020. Disponible en https://journals. sagepub.com/doi/10.1177/0486613413518724

Stiglitz, Joseph, 2008, "Is there a Post-Washington Consensus consensus?", en The Washington Consensus reconsidered, 41-56, Oxford University Press: Oxford.

Taylor, Marcus, 2006, From Pinochet to the third way: Neoliberalism and social transformation in Chile. Pluto Press: London. 
The New York Times, 2020, La pandemia amenaza con ampliar la desigualdad en América Latina. 11/07/2020, consultado e 21/08/2020, disponible en https:// www.nytimes.com/es/2020/07/11/espanol/america-latina/desigualdad-coronavirus-america-latina-colombia.html_

Universidad de los Andes, 2020a, El patrón socioeconómico del COVID El caso de Bogotá. Nota Macroeconómica 20, 18-05-2020, consultado el 14/08/2020, disponible en https://uniandes.edu.co/es/noticias/economia-y-negocios/el-patron-socioconomico-del-covid19-en-bogota

Universidad de los Andes, 2020b, Efectos en pobreza y desigualdad del Covid-19 en Colombia: un retroceso de dos décadas, Nota Macroeconómica 23. 11-082020, consultado el 20/08/2020, Disponible en https://uniandes.edu.co/sites/default/files/asset/document/notamacro20.pdf

Universidad del Rosario, 2018, Perfil actual de la informalidad en Colombia, 25/05/2018, consultado en septiembre 2020, disponible en https:/www.labourosario.com/post/2018/05/25/informe-perfil-actual-de-la-informalidad-en-colom-

bia-estructura-y-retos

Universidad Externado de Colombia Facultad de Economía, 2020, La desigualdad en el aseo personal y en la cuarentena. 14-08-2020, consultado en 20/09/2020, disponible en https://www.uexternado.edu.co/economia/la-desigualdad-en-elaseo-personal-y-en-la-cuarentena/

Williamson, John, 2008, "A short history of the Washington Consensus", en The Washington Consensus reconsidered, 14-30, Oxford University Press: Oxford.

World Health Organization, 2020, Covid-19, consultado el 25/09/2020, disponible en https://www.who.int/

Zamora, Roberto, 2012, Las ISAPRES en Chile, su institucionalidad jurídica y el derecho a la protección de la salud. Aplicación y Eficacia, Memoria de título, Universidad de Chile, Facultad de Derecho.

\section{RESUMEN CURRICULAR DE LOS AUTORES}

\section{Ciro Martínez Gómez}

Economista, Doctor en Demografía por la Universidad Autónoma de Barcelona. Actualmente consultor independiente. Se desempeñó como consultor sobre población y desarrollo en CELADE División de Población de la CEPAL en Santiago de Chile y en la oficina del UNFPA en Bogotá. Fue jefe de la división de población y la división de orientación del gasto en el Departamento de Planeación Nacional de Colombia y jefe de censos y demografía en el Departamento de Estadística de Colombia. Ha impartido docencia, entre otras, en la universidad Externado de Colombia, Javeriana y Nacional de Colombia, en varios países de América Latina y en Paris I, La Sorbona en Francia. Interesado en el relacionamiento de la población 
con el desarrollo económico y social, con la planeación y el diseño e implementación de las políticas públicas.

Dirección electrónica: clmgpers@gmail.com; ciromartinezg7@gmail.com

Carla Parraguez Camus

Es socióloga con maestrías en Políticas Públicas y en Estudios Sociales y Políticos Latinoamericanos. Obtuvo su Doctorado en Políticas Sociales en la Universidad de Birmingham, Inglaterra. Intelectualmente se interesa en los temas de desigualdad, daño social, políticas públicas, planeación estratégica y diseño de proyectos sociales.

Dirección electrónica: carliparraguez@gmail.com

Artículo recibido el 21 de octubre de 2020 y aprobado el 25 de enero de 2021. 